\title{
Understanding Desistance from Crime
}

\section{Citation}

Laub, John H., and Robert J. Sampson. 2001. Understanding desistance from crime. Crime and Justice 28: 1-69

\section{Published Version}

http://www.press.uchicago.edu/presssite/metadata.epl?mode=synopsis\&bookkey=34093

\section{Permanent link}

http://nrs.harvard.edu/urn-3:HUL.InstRepos:3226958

\section{Terms of Use}

This article was downloaded from Harvard University's DASH repository, and is made available under the terms and conditions applicable to Other Posted Material, as set forth at http:// nrs.harvard.edu/urn-3:HUL.InstRepos:dash.current.terms-of-use\#LAA

\section{Share Your Story}

The Harvard community has made this article openly available.

Please share how this access benefits you. Submit a story.

\section{Accessibility}




\section{Fobn H. Laub and Robert 7. Sampson}

\section{Understanding Desistance from Crime}

\section{A B S T R A C T}

The study of desistance from crime is hampered by definitional, measurement, and theoretical incoherence. A unifying framework can distinguish termination of offending from the process of desistance. Termination is the point when criminal activity stops and desistance is the underlying causal process. A small number of factors are sturdy correlates of desistance (e.g., good marriages, stable work, transformation of identity, and aging). The processes of desistance from crime and other forms of problem behavior appear to be similar. Several theoretical frameworks can be employed to explain the process of desistance, including maturation and aging, developmental, life-course, rational choice, and social learning theories. A life-course perspective provides the most compelling framework, and it can be used to identify institutional sources of desistance and the dynamic social processes inherent in stopping crime.

Why do they stop? Although the vast majority of criminal offenders stop committing crimes, desistance is not well understood. Criminology has been far more interested in the question, Why do individuals start? Most criminological research consists of cross-sectional "snapshots" or short-term panel studies of offending. There have been few long-term longitudinal studies of crime over the full life span. As a consequence, relatively little is known about desistance and, for that matter, the processes of persistent criminal behavior throughout the

John H. Laub, professor of criminology at the University of Maryland, College Park, and Robert J. Sampson, professor of sociology at the University of Chicago, gratefully acknowledge the research assistance of Elaine Eggleston and Chris Kenaszchuk and thank Frank Cullen, Jeffrey Fagan, Shadd Maruna, Alex Piquero, Michael Tonry, Chris Uggen, and two anonymous reviewers for their insights and suggestions.

(C) 2001 by The University of Chicago. All rights reserved.

0192-3234/2001/0028-0001\$2.00 
life course. Indeed, the characteristics that distinguish persistence in a life of crime from desistance within any group of high-risk offenders are generally unknown.

Criminological theories are not silent on why most offenders usually stop. For example, Akers argues, "other than one's own prior deviant behavior, the best single predictor of the onset, continuation, or desistance of delinquency is differential association with law-violating or norm-violating peers" (1998, p. 164). Despite a lack of systematic research, there is no shortage of theoretical speculations (see also Agnew 1997; Matsueda and Heimer 1997). This has not always been the case. One of the most powerful critiques of criminological theory was offered by David Matza in his classic book, Delinquency and Drift (1964), in which he introduced the idea of "maturational reform" to explain why most delinquency was transient and situational and why, as adolescents grew up, they simply left delinquency behind. He concluded that "most theories of delinquency take no account of maturational reform; those that do often do so at the expense of violating their own assumptions regarding the constrained delinquent" (Matza 1964, p. 22).

In this essay we examine theory and both quantitative and qualitative research on desistance from crime and other problem behaviors (such as alcohol and drug abuse). From this body of knowledge, it is clear that a number of factors are associated with desistance from crime. Elements such as family formation and gaining employment, for example, appear to predict desistance from crime in adulthood. But the research evidence is not strong or convincing. To cite but one example, in an extensive review of the literature, Wright and Wright (1992, p. 54) concluded that "no clearly confirming set of findings has emerged from research to date that demonstrates that getting married and having children reduces the likelihood of criminal offense." In order to make sense of this small but growing line of research, we organize our overview within several explanatory frameworks. We believe this strategy offers the best hope of making sense of the accumulated research literature. We also present a life-course perspective on desistance based on our long-term study of crime and deviance over the life span. The goal is not to present a full-blown theory but to offer a theoretical framework that identifies the key sources of change in the desistance process and begins to specify the causal mechanism involved. We also examine the implications of the life-course framework as a guide to future research on desistance. 
From a theoretical standpoint, understanding desistance from crime requires a theory of crime and the criminal "offender." Desistance cannot be understood apart from the onset of criminal activity and possible continuation in offending over time. Whether or not one embraces the criminal career paradigm (Blumstein et al. 1986), good theories of crime ought to account for the onset, continuation, and desistance from criminal behavior across the life span. We believe a life-course perspective offers the most compelling framework for understanding the processes underlying desistance and the role of social context in shaping the dynamics of desistance. Specifically, we advance a life-course theory of age-graded informal social control as a means of understanding both the onset of and desistance from criminal behavior (Sampson and Laub 1993). Without a theory of crime, researchers and policy makers would be better off dropping the term "desistance" from their lexicon and focusing on the presence or absence of recidivism (Hoffman and Beck 1984).

Some researchers have argued that the policy ramifications from the study of desistance are clear and direct. For example, Uggen and Piliavin assert that desistance researchers have a "more legitimate and expansive license to intervene in the lives of participants" (1998, p. 1413). Moreover, they insist that the conditions of desistance are "much more amenable" to manipulation compared with the conditions of offending. Understanding the factors that lead to desistance is important in shaping interventions that reduce reoffending among those already involved in crime. This moves the field away from the narrow but now fashionable idea that prevention strategies administered early in the life course are the only feasible strategies to reduce criminal behavior.

We reach several conclusions. More attention should be devoted to the conceptualization and measurement of desistance. It is useful to distinguish desistance as a process from termination of criminal activity as an event, and we offer examples of its confounding in current research. On the basis of our review of the literature, desistance stems from a variety of complex processes-developmental, psychological, and sociological - and thus there are several factors associated with it. The key elements seem to be aging; a good marriage; securing legal, stable work; and deciding to "go straight," including a reorientation of the costs and benefits of crime. Processes of desistance from crime in general, specific types of crime, and multiple forms of problem behavior seem to be quite similar.

Although several theoretical frameworks provide a plausible explana- 
tion of desistance, the life-course perspective provides the most beneficial approach to understanding both persistence in and desistance from crime because of its explicit focus on the unfolding of lives in social context. To buttress this argument, we highlight new findings from our long-term follow-up study (Laub and Sampson 2001) of 500 delinquents at age seventy. Our life-history, narrative data underscore the need to examine desistance as a process consisting of interactions between human agency, salient life events, and historical context.

We conclude the essay by offering explicit ideas to guide future research and by considering the implications of our survey for crime control policies. We discuss ways to better identify, specify, and eventually understand the causal mechanisms supporting the desistance process. Integrating quantitative and qualitative methods offers the best strategy for furthering this agenda. With respect to policy concerns, and consistent with our life-course framework, current policies of incarceration are unlikely to foster desistance from crime in the long run.

These themes are organized as follows. Section I examines the conceptual, definitional, and measurement issues relating to desistance from crime. Both quantitative and qualitative studies of desistance are considered in Section II, including research on criminal careers, studies of recidivism, and studies with a specific emphasis on desistance from crime. Section III summarizes research on desistance from domestic violence and other problem-related behaviors. We organize the small, but growing body of literature on desistance into several explanatory frameworks in Section IV. These conceptual accounts include maturation and aging, developmental, life course, rational choice, and social learning. In Section V, we present a life-course perspective on desistance from crime drawing on our long-term follow-up study of juvenile delinquents. Using life-history narratives we address processes of desistance over the full life span, with a focus on middle age. Section VI discusses the implications for future research and policy on desistance from crime.

\section{Desistance and Pornography: Do We Know It When We See It?}

Although desistance is a major component of the criminal career model (Blumstein et al. 1986), it is the "least studied process" (Loeber and LeBlanc 1990, p. 407; see also Farrington 1986, pp. 221-23) compared with research on onset, persistence, and escalation in criminal offending. 


\section{A. Conceptual Issues}

Defined as ceasing to do something, "desistance" from crime is commonly acknowledged in the research literature. Most offenders, after all, eventually stop offending. Yet there is relatively little theoretical conceptualization about crime cessation, the various reasons for desistance, and the mechanisms underlying the desistance process. As Maruna noted, "Desistance from crime is an unusual dependent variable for criminologists because it is not an event that happens, but rather it is the sustained absence of a certain type of event (in this case, crime)" (2001, p. 17). Compounding this lack of conceptualization is the confounding of desistance with aging. It is well known that crime declines with age in the aggregate population (Gottfredson and Hirschi 1990). The decline of recidivism with age led Hoffman and Beck to argue for the existence of an age-related "burnout" phenomenon $(1984$, p. 621$)$. These authors found that rates of recidivism decline with increasing age and that this relationship maintains, controlling for other factors linked to recidivism such as prior criminal record. Moreover, there is evidence that offenders change as they age (see, e.g., Shover 1985, 1996; Cusson and Pinsonneault 1986). It appears that both formal and informal social controls become more salient with age. For example, fear of doing time in prison becomes especially acute with age (see Shover 1996).

As Rutter (1988, p. 3) has pointed out, one question is whether predictors of desistance are unique or simply the opposite of predictors leading to offending. To date, it appears that most predictors of desistance are the reverse of risk factors predicting offending (LeBlanc and Loeber 1993, p. 247). For example, Farrington (1992) contends that the onset of antisocial behavior is due to changes in social influence from parents to peers and that desistance is due to changes in social influence from peers to spouses. This indicates that the predictors of desistance are distinguished from the predictors of the onset of crime. This finding was evident in the Gluecks' research on criminal careers conducted in the 1930s and 1940s (see, e.g., Glueck and Glueck 1943). Recently, Uggen and Piliavin (1998) referred to this idea as "asymmetrical causation."

According to Loeber and LeBlanc, desistance does not occur "merely as a function of individuals' chronological age" (1990, p. 452). One reason for this is that desistance can take place at any time during the life span. The factors involved in desistance are different at different ages. That is, early desistance, before age eighteen, is likely to be 
different from late desistance, after age thirty (Weitekamp and Kerner 1994). Also, it may be that desistance at the same age is different for those with early versus late onset of criminal offending (Tremblay 1994). Nevertheless, based on the available data, desistance occurs most often during and after adolescence. Based on the evidence, desistance is normative for most offenders. Moffitt, for example, has written, "Indeed, numerous rigorous self-report studies have now documented that it is statistically aberrant to refrain from crime during adolescence" (1994, p. 29). This makes the lack of conceptualization of desistance from crime even more of a mystery.

Several serious conceptual questions remain unanswered. For example, Can desistance occur after one act of crime? If so, are the processes of desistance from a single act of crime different from desistance after several acts of crime? Is there such a thing as "spontaneous remission" and, if so, can the term be precisely defined? For example, Stall and Biernacki (1986) define spontaneous remission as desistance that occurs absent any external intervention. How can "genuine desistance" be distinguished from "false desistance"? How long a followup period is needed to establish desistance? Baskin and Sommers argue that a two-year hiatus indicates "temporary cessation" and is a long enough period to consider the "processes that initiate and sustain desistance" (1998, p. 143). How can "intermittency in offending" be distinguished from "true desistance"? For instance, Elliott, Huizinga, and Menard (1989, p. 118) employ the term "suspension" because suspension implies either temporary or permanent cessation. Farrington has stated, "even a five-year or ten-year crime-free period is no guarantee that offending has terminated" (1986, p. 201). Barnett, Blumstein, and Farrington (1989) found a small group of offenders who stopped offending and then restarted after a long time. What role does death or serious physical injury play in the study of desistance? Reiss (1989, pp. 229-39) has emphasized that criminologists tend mistakenly to assume that desistance is always a voluntary decision. The fact is that high-rate offenders are more likely to exit the risk pool through death (see, e.g., Lattimore, Linster, and MacDonald 1997). Should de-escalation to less serious offending be seen as an indication of desistance? In a similar vein, if offending ceases, but problem behavior remains or increases, what does that say about desistance? Weitekamp and Kerner note, "Desistance of crime could quite contrarily be considered as a process which may lead to other forms of 
socially deviant, unwanted or personally dreadful problems" (1994, p. 448). All of these issues raise fundamental questions about the meaning of desistance. ${ }^{1}$ Answers to these and other questions are not found in the research literature.

At the heart of the conceptual questions is a conception of stability and change over the life course. Does desistance occur when there is a change in one or more of the following domains: crime, criminality, or opportunity? Is desistance related to one, two, or all three indicators? Defining criminality as the propensity to offend, Gottfredson and Hirschi (1990) argue that desistance occurs when there is a change in crime or opportunity. In their view, propensities to crime are stable over the life course and thus could not account for desistance from crime. Like Gottfredson and Hirschi, we maintain that crime changes over time (Sampson and Laub 1993), but we also contend that opportunities for crime are ubiquitous (Sampson and Laub 1995). However, so far we have been silent as to whether criminality (propensity) changes or remains stable over time, although we imply that traits like self-control can change over time as a consequence of changes in the quality or strength of social ties.

Ultimately, the concern with propensity (assuming that such an entity exists) may not be an important issue. LeBlanc and Loeber, for example, recognize that "manifestations of deviancy in the course of individuals' lives may change, while the underlying propensity for deviancy may remain stable" (1998, p. 179). Perhaps the focus ought to be on the heterogeneity of criminal behavior over the life span and not some unobserved latent concept. ${ }^{2}$

\footnotetext{
${ }^{1}$ Similar questions have been raised regarding the vocabulary and conceptualization of "displacement" and crime. For example, Barr and Pease (1990) have suggested that "deflection of crime from a target" is a better and more accurate formulation than displacement.

${ }^{2}$ Bushway et al. (2001) take a purely empirical approach to studying desistance as a process by offering a statistical model for changes in the rate of offending over time. They argue that "to study change (i.e., change that can be explained), we need to explicitly shift our focus from observed behavior to the underlying propensity to offend" (Bushway et al. 2001, p. 6). In their paper, Bushway and his colleagues endorse semiparametric trajectory models (Nagin and Land 1993) as the best method to capture changes in propensity to offend. Whether their statistical conceptualization of desistance offers a new approach compared with earlier conceptualizations remains to be seen. To us, the implications of their paper for qualitative research on desistance from crime are not readily apparent. Moreover, a strict focus on a latent (or unobserved) propensity to offend - the road taken by Bushway et al. (2001) - assumes but does not articulate a particular kind of individual-level theory.
} 


\section{B. Definitional Issues}

A clear and precise definition of desistance cannot be developed that is separate from a clear and precise research question. ${ }^{3}$ Developing a definition of desistance for the sake of having a definition is not worth the effort. Currently, there is no agreed-upon definition of desistance (see Bushway et al. 2001). ${ }^{4}$ Some definitions are vague. For example, Shover defined desistance as the "voluntary termination of serious criminal participation" (1996, p. 121). Other definitions are arbitrary. For instance, Farrington and Hawkins (1991) defined desistance as having no convictions between ages twenty-one and thirty-two following a conviction before age twenty-one. Others are so idiosyncratic to a study or a data set that they are hard to defend. For example, Warr (1998) defined desistance as reporting smoking marijuana during the year preceding wave 5 interviews in the National Youth Survey but not reporting any such incidents in the year preceding wave 6 . Other definitions do not sound like desistance at all. Clarke and Cornish write, "Desistance is, in any case, not necessarily permanent and may simply be part of a continuing process of lulls in the offending of persistent criminals . . . or even, perhaps, of a more casual drifting in and out of particular crimes" (1985, p. 173). Finally, some researchers do not define desistance but purport to study it (see, e.g., Trasler 1979)!

Weitekamp and Kerner (1994) have tried to disentangle the various components of desistance. They define termination as the time when the criminal or delinquent behavior stops permanently. In contrast, suspension is defined as a break in offending behavior. These authors also view desistance as a process (not an event) by which frequency of offending decelerates and exhibits less variety (see Maruna [2001] and Bushway et al. [2001], who also take the position that desistance is a process, not an event). Weitekamp and Kerner (1994) recommend abandoning the notion of "spontaneous remission" in the study of desistance, arguing that the concept is unclear and theoretically barren.

In a similar vein, Loeber and LeBlanc (1990, p. 409) tried to disentangle desistance by specifying four components of the term: a slowing down in the frequency of offending (deceleration); a reduction in the

\footnotetext{
${ }^{3}$ Defining persistence in crime suffers the same problem, for there is no standard agreed-upon definition. For example, Wolfgang defined persistent offenders as those having an arrest as a juvenile and as an adult (1995, p. 143). Definitions should not be distinct from research questions.

${ }^{4}$ In fact, an editor of a leading journal once asked us to remove the term from our paper. He argued that "desistance" was not a word. There appears to be no agreed-upon spelling either.
} 
variety of offending (specialization); a reduction in the seriousness of offending (de-escalation); and remaining at a certain level of seriousness in offending without escalating to more serious acts (reaching a ceiling).

\section{Measurement Issues}

There are, of course, serious measurement problems inherent in assessing desistance if for no other reason than that there is ambiguity and imprecision in the study of crime in general. Even though some offenders desist from criminal activity, they may continue to engage in a variety of acts that are considered "deviant" or the functional equivalents of crime (Gottfredson and Hirschi 1990). For example, they may drink alcohol excessively, have children out of wedlock, "loaf" instead of work, gamble, and congregate in bars. Can such actors accurately be called desisters? Perhaps from the narrow confines of the criminal justice system they are, but from a theoretical vantage point, they display behaviors that imply little change in their antisocial trajectory.

As Barnett and Lofaso (1985) have argued, the paucity of data on criminal behavior in later life means that findings on desistance (or the age of termination) may reflect the cutoff of observations at a specific age (i.e., "false desistance") rather than a true cessation of criminal activity. Termination that is followed by criminal involvement can be considered "false" desistance as well (Blumstein, Farrington, and Moitra 1985). The length of follow-up in the measurement period thus seems crucial. Vaillant (1996) noted that in research on alcohol treatment the typical follow-up period is six months to a year. In his longterm follow-up study of male alcohol abuse over a thirty-year period, Vaillant (1996) concluded that two years of abstinence is inadequate to provide a basis for long-term prognosis. He also reported data from a follow-up study of alcohol-dependent men and women showing that 45 percent relapsed after two years of abstinence. Yet only 9 percent relapsed after five years of abstinence. The standard in research on narcotic drug users seems to be a three-year follow-up period; research on cancer typically examines remission five years after onset (Vaillant 1996). In criminological studies the follow-up periods vary considerably, but most are fairly short-six months to a year or two.

An important paper by Nagin, Farrington, and Moffitt (1995) bears on this issue. They found, based on official records of conviction from the Cambridge Study of Delinquent Development, that a group of offenders desisted from crime (starting at age twenty) even though 
self-reported data from these same subjects revealed continued involvement in drugs, alcohol, and violence outside of the home at age thirty-two. Like Nagin, Farrington, and Moffitt (1995), LeBlanc and Frechette (1989) found varying rates of desistance depending on the source of information. Using official records as the criterion, 62 percent of the official delinquents desisted from crime. However, using self-report data, only 11 percent of the males desisted by age thirty.

\section{Summary Framework}

Like many criminological topics, the topic of desistance elicits conceptual, definitional, and measurement concerns. These are important and demand further theoretical and research attention. In order to increase clarity and provide guidance, we believe two issues stand out.

First, the concepts of desistance and termination of offending cannot be meaningfully studied independent of a conception of crime and the offender. Crime is typically defined as a violation of societal rules of behavior that are embodied in law. When officially recognized, such violations may evoke sanctions by the state. Deviance is typically defined as violations of social norms or generally accepted standards of society (i.e., institutionalized expectations). Even given these definitions, the operational definition of an "offender" remains ambiguous, as does the point at which desistance occurs. How much offending must ensue before one is defined as an "offender"-one, five, ten, twenty acts? And over what period of time must a former offender be "free" of crime before we say that he or she has desisted-a year, ten years?

Although answers to these questions are difficult, some ground rules are possible. Because low-rate offending is normative, especially during adolescence, criminologists should not spend much time or energy theorizing why everyone seems to commit crime during their teen years. Following this logic, criminologists should also not spend much time or energy studying termination and desistance for low-rate offenders (defined as involvement in a single event or a series of relatively isolated events over a long period of time). Furthermore, termination and desistance should be studied among those who reach some reasonable threshold of frequent and serious criminal offending. The precise details of measurement depend on the data set and the research question under investigation. For example, in previous research we have argued for a focus on desistance from persistent and serious delinquency, operationalized as a group of 500 formerly incarcerated juve- 
niles with lengthy and serious criminal records (Sampson and Laub 1993). We return to these definitional issues below, for their resolution is crucial to advancement of research.

Second, once an operational definition of the offender pool has been constructed and defended, we believe it is important to distinguish termination of offending from the concept of desistance. Termination is the time at which criminal activity stops. Desistance, by contrast, is the causal process that supports the termination of offending. While it is difficult to ascertain when the process of desistance begins, it is apparent that it continues after the termination of offending. In our view, the process of desistance maintains the continued state of nonoffending. Thus, both termination and the process of desistance need to be considered in understanding cessation from offending. By using different terms for these distinct phenomena, we separate termination (the outcome) from the dynamics underlying the process of desistance (the cause), which have been confounded in the literature to date. ${ }^{5}$

Perhaps an analogy would be helpful. Marriage is an institution that is marked by a time when it officially starts (date of marriage) and, in many cases, ends (date of divorce). One may thus be said to enter the state of marriage at a discrete point. In this regard, marriage is like offending, which is also marked by an event (the commission of a crime) that occurs at a point in time. Divorce is likewise an event and can be viewed as analogous to termination from offending. One difference, however, is that divorce is fixed in time (e.g., the date of legal separation), whereas termination of offending is characterized by the absence of continued offending (a nonevent). Unlike, say, stopping smoking, where setting a specific quit date is often important, criminal offenders typically do not set a date to quit offending. The period of time necessary to establish that termination has occurred is a sticky issue but one that is possible to overcome. For example, in the criminal career literature, the end of the criminal career is defined as the age at which the last crime is committed (Blumstein et al. 1986). In this case

${ }^{5}$ In a similar vein, Hirschi and Gottfredson (1986) developed the distinction between crime and criminality to capture the idea that crime declines with age while criminality remains stable. They argue, "those concerned with maturational reform appear to confuse change in crime (which declines) with change in criminality (which may not change at all). Part of the reason for this confusion is that we tend to use the same indicator for both concepts. A count of criminal acts serves as a measure of crime and as a measure of criminality" (Hirschi and Gottfredson 1986, p. 58). With respect to stopping offending, the same indicators and processes are used to describe both termination and desistance. 
it seems reasonable to specify the date of last crime as the point of termination of offending.

Following Vaughan (1986), we consider the concept of "uncoupling" to be clarifying. Vaughan defined uncoupling as the process of divorce and separation, which occurs prior to, during, and after the event of divorce. Like desistance, uncoupling is not abrupt but a gradual transition out of an intimate relationship. We believe that, just like quitting smoking or uncoupling (Vaughan 1986; Fisher et al. 1993), desistance is best viewed as a process rather than a discrete event. The process is a social transition that entails identity transformation, as from a smoker to a nonsmoker, from a married or coupled person to a divorced or uncoupled person, or from an offender to a nonoffender. Also, like quitting smoking or uncoupling, desistance is not an irreversible transition.

In short, by focusing attention on the conceptual, definitional, and measurement issues surrounding termination and desistance from crime, we urge researchers to make their definitions more explicit and provide details regarding the measurement of these concepts. For purposes of this essay, we focus on research that is directed toward discovering the predictors of termination from persistent offending and "unpacking" the causal dynamics of the processes of desistance. To the extent possible, we examine the multiple social contexts of desistance. LeBlanc and Loeber point out that desistance is embedded in developmental contexts as well, such as a decrease in physical strength and fitness with age (1998, p. 166). We thus emphasize the variety of contexts-developmental, historical, and environmental-that bear on termination and the processes of desistance from crime.

\section{Predictors and Processes of Desistance: What Do We Know?}

We draw on three bodies of literature-criminal careers research, recidivism studies, and qualitative studies of offenders and ex-offenders-to frame what we know about the predictors and processes of desistance from crime. To the extent possible, special attention is devoted to differences in desistance across offender characteristics (e.g., males vs. females) and by crime type (e.g., robbery vs. burglary vs. spouse assault). Relevant literature pertaining to cessation from other problem behavior and deviance (e.g., illicit drug use and alcohol abuse) is incorporated where appropriate. It is important to point out that we do not systematically review the research literature that focuses solely 
on the prevalence of desistance. It is our assessment that desistance rates vary so much across sampling and measurement conditions that they are virtually meaningless when taken out of context.

Despite clear limitations in data and serious weaknesses in study designs, several important findings in the previous research relating to the predictors and processes of desistance from crime should be underscored. First, the prevalence of crime declines with age, although there appears to be more variability in the age distribution across offense types than is commonly believed (see Steffensmeier et al. 1989). Thus, desistance is part and parcel of the natural history of offending. Second, the incidence of offending does not necessarily decline with age and may increase with age for certain types of criminal activity and subgroups of offenders (Blumstein et al. [1986]; Farrington [1986]; for an opposite view, see Hirschi and Gottfredson [1983]). Third, there is substantial continuity in offending from childhood to adolescence and into adulthood, and the earlier the onset of criminal activity, the longer the criminal career. Fourth, despite patterns of continuity, there is a great deal of heterogeneity in criminal behavior over the life span because "many juvenile offenders do not become career offenders" (Cline 1980, p. 670). From a theoretical perspective, rather than thinking in simplistic, rigid offender/nonoffender categories, Glaser (1969) suggests that it is more appropriate to view criminality dynamically as a "zigzag path" consisting of crime and noncrime cycles. Along similar lines, Matza (1964) offers the image of "drift" to capture the instability of offending over time. Finally, the literature focusing directly on desistance indicates that there are multiple pathways to desistance. Some of the most important seem to be attachment to a conventional other such as a spouse, stable employment, transformation of personal identity, and the aging process. These predictors and processes of desistance do not seem to vary much by offender characteristics or type of crime.

\section{A. Studies of Criminal Careers and Desistance}

Sheldon and Eleanor Glueck may have been the first researchers to examine the relationship between age and criminal behavior over the life span, including age at termination of offending. In their fifteenyear follow-up of 510 male reformatory inmates, they found that the proportion of subjects arrested decreased from 71 percent in the first five-year follow-up period to 57 percent in the third five-year followup period (Glueck and Glueck 1943, p. 109). However, the average 
number of arrests among those arrested increased from 3.3 to 3.6 across the same follow-up periods. Arrests for property crimes declined, but they were replaced by arrests for drunkenness. The average age of the subjects at the end of the fifteen-year follow-up was forty (Glueck and Glueck 1943, p. 3). Similar patterns can be found in the Gluecks' fifteen-year follow-up of 1,000 juvenile delinquents referred to the Judge Baker Clinic (Glueck and Glueck 1940) and their followup of 500 juvenile delinquents from the Unraveling Fuvenile Delinquency study (Glueck and Glueck 1950, 1968).

The Gluecks did not systematically investigate the causes of the decrease in offending over time, although they did compare the reformed and unreformed as well as those who remained serious offenders compared with those who de-escalated to minor offending. ${ }^{6}$ The Gluecks concluded that those who reformed "were better circumstanced than those who continued to recidivate over the long-term follow-up span" (Glueck and Glueck 1974, p. 141). Many of these differences were due to varying experiences, personal traits, and circumstances before the onset of offending. From these findings, the Gluecks developed the hypothesis of "delayed maturation" to explain desistance from crime, which we discuss below.

In another seminal research project, subjects from the CambridgeSomerville Youth Study have been followed into their forties (median age, forty-seven). McCord (1980) found that while the vast majority of juvenile delinquents committed a crime as an adult, the majority of the adult offenders had no history of offending as juveniles. McCord also reported that the earlier the age of onset, the greater the likelihood of recidivism in adulthood.

Lee Robins's (1966) follow-up study of child guidance clinic patients is also pertinent to the topic of continuity and change in offending over time. Robins found that 72 percent of the male children referred to the clinic for antisocial behavior were arrested between the ages of eighteen and thirty. Of those arrested between age eighteen and thirty, 59 percent were arrested after age thirty. Conversely, of those not arrested between age eighteen and thirty, 18 percent were arrested after age thirty (Robins 1966, p. 47). Thus, while these data show continuity of offending well into middle age, they also suggest that "the effect of the early experience begins to diminish after age thirty and recent experiences become more significant" (Cline 1980, p. 666).

${ }^{6}$ The Gluecks defined reform as an absence of criminal activity during follow-up. 
Wolfgang, Thornberry, and Figlio (1987) followed a sample from the 1945 Philadelphia birth cohort study (Wolfgang, Figlio, and Sellin 1972) to age thirty. They reported strong continuity in offending across the juvenile and adult years. The peak age of offending is sixteen, and thereafter the rate of offending declines into adulthood. Wolfgang, Thornberry, and Figlio also found that "the average number of offenses committed at each age is relatively constant from ages ten to thirty" (1987, p. 41). In the successor study to Wolfgang, Figlio, and Sellin (1972), Tracy and Kempf-Leonard (1996) collected criminal records up to age twenty-six for 27,160 males and females from a 1958 Philadelphia birth cohort (see also Tracy, Wolfgang, and Figlio 1985). The vast majority of cohort subjects had no record of delinquency or adult crime (71 percent). Six percent committed crimes only as adults and 8 percent committed criminal acts in both the juvenile and adult period. Sixteen percent of the cohort had a record of delinquency but no official contact in adulthood. About two-thirds ( 68 percent) of the cohort delinquents did not continue offending in adulthood (Tracy and Kempf-Leonard 1996, pp. 80-81).

There is empirical evidence that similar criminal career patterns exist in European countries. In the Cambridge Study in Delinquent Development, Farrington and his colleagues (1988) reported considerable continuity in offending from adolescence to adulthood (defined as age thirty-two). As in the U.S. studies, age of onset predicted persistence in offending. Farrington et al. (1988) also reported that the prevalence of convictions peaked at age seventeen and then declined. It is interesting to note that they found that the sample as a group committed as many offenses between ages twenty-one and thirty-two as in the juvenile and young adulthood periods. The prevalence of certain offenses (e.g., theft from work, assault, drug use, and fraud) did not decline with age.

Stattin and Magnusson (1991) studied a Swedish cohort of 709 males and found a strong connection between criminal activity in childhood (up to age fourteen), adolescence (from fifteen to twenty), and early adulthood (twenty-one to thirty). They also found little onset of offending during the adult period (see also Stattin, Magnusson, and Reichel 1989). These findings of continuity in offending are consistent with the results of another study of the criminal activity of Swedish males in adolescence and adulthood from an older cohort (see Sarnecki 1985).

Overall, criminal career research leads to the clear and nonsurpris- 
ing conclusion that juvenile delinquency is linked to adult crime. The percentage of juvenile delinquents known to the police that persist as adult offenders ranges from 31 to 71 percent (Blumstein et al. 1986, p. 87). Hence, the juvenile record is a strong predictor of later offending, and this relationship increases as the juvenile record becomes longer (Blumstein et al. 1986, pp. 86-88). At the same time, and perhaps surprisingly, " 40 to 50 percent of adult offenders do not have records of juvenile police contacts" (Blumstein et al. 1986, p. 88). There is an apparent paradox at work here. While studies we reviewed show that "antisocial" behavior in children is one of the best predictors of antisocial behavior in adults, "most antisocial children do not become antisocial as adults" (Gove 1985, p. 123). ${ }^{7}$ Cline states that although there is "more constancy than change ... there is sufficient change in all the data to preclude simple conclusions concerning criminal career progressions" (1980, p. 665). He concludes, rightfully, we suggest, that there is far more heterogeneity in criminal behavior than previous work has suggested, and that many juvenile offenders do not become career offenders (Cline 1980, pp. 669-70). Loeber and LeBlanc make a similar point: "Against the backdrop of continuity, studies also show large within-individual changes in offending" (1990, p. 390).

A focus on parameters of the criminal career-onset, participation, incidence, and career length-is the essence of a criminal career approach to the study of crime and criminals. Most important, the criminal career model recognizes that there is a mixture of offending patterns and highlights the need to disaggregate the offender population. The criminal career model takes as a given that causal factors explaining participation in crime, the frequency of offending, and the termination of a criminal career are different. Indeed, a key idea of this approach is that high-rate offenders are distinctive; namely, they have a stable rate of offending and hence do not desist from crime. As

${ }^{7}$ We set aside a detailed discussion of the problematic notion of the concept of "antisocial" behavior. We would emphasize two points, however, that bear on desistance. First, antisocial behavior is in fact social in the sense that it is group or interactional behavior. Second, our understanding of antisocial behavior cannot be considered independent of societal reactions and definitions. For example, the major contributing factor to the dramatic rise in imprisonment rates in the United States and many other countries over the past twenty years, especially of minority groups, has been drug arrests. This has resulted from a shift over time in how the same behavior (taking drugs) is labeled by society. Is drug use (and hence lack of desistance) inherently antisocial? Moreover, the State decision to label and incarcerate someone for drug use bears on the life course of that individual, which may contribute in turn to further "antisocial" behavior or lack of desistance. For these reasons sociologists have been reluctant to embrace antisocial behavior as a concept (see Sampson 2000). 
Blumstein and Cohen state, "The common belief that offenders who remain in their criminal careers into their 30 s will imminently terminate their careers is not empirically justified. On the contrary, those offenders who are still actively involved in crime at age 30 have survived the more typical early termination of criminal careers, and so are more likely to be the more persistent offenders. After their early 40s, however, their termination rates are quite high" (1987, p. 991; see also Piquero et al. 2001). These offenders are characterized by early onset of offending, high frequency of prior offending, drug use, and unstable employment.

Desistance is referred to as age of termination or career length in the criminal career lexicon, with the fundamental finding that early onset is linked to a longer career. Existing research on the length of criminal careers indicates that most careers are short-five years for offenders who are active in index offenses as young adults (Blumstein et al. 1986, p. 94, but see Farrington, Lambert, and West 1998). For offenders who are still active in their thirties, the residual career length is about ten years (Blumstein et al. 1986, p. 94). Yet the data supporting these conclusions are not without problems. Because of the separation of juvenile and adult record-keeping systems in the United States, many studies of criminal careers have focused on either juveniles or adults. Even more concerning is that the bulk of this research reflects the cutoff of observations at a given age, thus artificially marking the length of criminal careers. Almost all criminal career research has also limited itself to officially defined data on crime.

Overall, the criminal career approach represents a significant movement in criminology, but it appears to have reached a point of stagnation. The reasons are many, but our diagnosis is that the approach faltered because of its narrow focus on measurement and policy. The focus on desistance has been used to enhance the predictive accuracy of criminal career models to identify high-rate offenders prospectively for purposes of incapacitation (see, e.g., Blumstein, Farrington, and Moitra 1985; Barnett, Blumstein, and Farrington 1989). As a result, theoretical accounts of desistance stemming from this body of research (with few exceptions) have been sorely lacking.

\section{B. Studies of Recidivism and Desistance}

Although not necessarily within the criminal career paradigm, a small number of investigators have explicitly examined recidivism and desistance using longitudinal data. A follow-up of 200 Borstal boys 
found that marriage led to "increasing social stability" (Gibbens 1984, p. 61). Knight, Osborn, and West (1977) discovered that while marriage did not reduce criminality, it reduced antisocial behavior such as drinking and drug use (see also Osborn and West 1979; West 1982). Osborn (1980) examined the effect on delinquency of leaving London and found that subjects who moved had a lower risk of reoffending when compared with a similar group who stayed (see also West 1982). There is some evidence that episodes of unemployment lead to higher crime rates (Farrington et al. 1986). Along similar lines, Glaser's extensive study of parolees and recidivism showed that "men in prison have expectations of extremely rapid occupational advancement during the years immediately following their release, expectations which are unrealistic in light of their limited work experience and lack of vocational skills" (Glaser 1969, p. 238). Glaser found that lack of skill and work experience were the major obstacles to finding a good job and that job instability was in turn linked to criminal recidivism.

Trasler (1979) examined the idea of "spontaneous desistance" from crime. For Trasler, desistance stems from a response to changes in the contingencies of reinforcement. In other words, situational changes led to desistance. These adult reinforcers included a job, an adequate income, a home, a wife, children, and adult friends (Trasler 1979, p. 316).

In an effort to assess the effect of several transitional life events on desistance from crime, Rand examined data for 106 male offenders from the follow-up study of the 1945 birth cohort in Philadelphia. Rand (1987) found no effect on desistance for fatherhood, serving in the military, vocational training, or going to college. Moreover, other transitional life events (e.g., cohabitation) were positively related to crime. Marriage, completing high school, and receiving vocational training in the military were related to reduced criminal involvement, but the results varied considerably by offender characteristics as well as crime-related characteristics.

Farrington and Hawkins (1991) analyzed data from the Cambridge Study of Delinquent Development to assess the characteristics of desisters compared with persisters in adulthood. From this prospective longitudinal study of 411 London males that started when the boys were eight or nine, they found no relationship between factors influencing prevalence, early onset, and desistance. For example, early troublesome behavior was an important predictor of both participation in offending and early onset of crime, yet this variable was not strongly related to 
persistence in criminal behavior in adulthood (Farrington and Hawkins 1991, p. 28). However, father's participation with the boy in leisure activities was associated with a later onset and desistance from crime even when controlling for parental criminality (Farrington and Hawkins 1991, p. 19). Along with parental involvement, commitment to school was also associated with desistance from crime.

Loeber et al. (1991) studied desistance in juvenile offending using data from the Pittsburgh Youth Study, a longitudinal study of boys and their primary caretakers. They found several variables that were associated with desistance in offending, including low social withdrawal or shyness, low disruptive behavior, and positive motivational and attitudinal factors (Loeber et al. 1991, p. 37). Even more intriguing was the finding that different factors emerged for early desistance (prior to age twelve) and later desistance (ages thirteen to fourteen) (Loeber et al. 1991, pp. 73, 81). Unlike other researchers, Loeber et al. (1991, p. 81) found that most factors associated with initiation were also associated with desistance. Loeber and his colleagues concluded, "Initiation and desistance appear to reflect the positive and negative aspects of a similar process" (1991, p. 81). LeBlanc and Loeber (1998) also showed that rates of desistance varied by crime type as well as type of problem behavior. In addition, age at termination was associated with age of onset and seriousness of the offense, with the most serious offenses ceasing at an advanced age and less serious offenses ceasing at earlier ages.

In our book, Crime in the Making (Sampson and Laub 1993), we developed an age-graded theory of informal social control to explain crime and deviance over the life course. Most relevant for the study of desistance is the idea that salient life events and social ties in adulthood can counteract, at least to some extent, the trajectories apparently set in early child development. Our thesis is that social bonds in adulthood-especially attachment to the labor force and cohesive marriage-explained criminal behavior independent of prior differences in criminal propensity. In other words, pathways to both crime and conformity were modified by key institutions of social control in the transition to adulthood (e.g., employment, military service, and marriage). Thus, strong social bonds could explain desistance from criminal behavior in adulthood, despite a background of delinquent behavior.

We tested these ideas using data from the Gluecks' classic study of juvenile delinquency and adult crime (Glueck and Glueck 1950, 1968). We found that despite differences in early childhood experiences, adult social bonds to work and family had similar consequences for the life 
trajectories of the 500 delinquents and 500 nondelinquent controls. That is, job stability and marital attachment in adulthood were significantly related to changes in adult crime-the stronger the adult ties to work and family, the less crime and deviance among both delinquents and controls. We conceptualized various types of change and argued that social control and turning points were crucial in understanding processes of change in the adult life course (see Laub and Sampson 1993). These concepts were portrayed by examining personbased, life-history data drawn from the Gluecks' longitudinal study of 1,000 men (Glueck and Glueck 1968). Although adult crime was clearly connected to childhood behavior, these qualitative data suggested that both incremental and abrupt change were structured by changes in adult social bonds. Integrating divergent sources of lifehistory data (e.g., narratives, interviews), our qualitative analysis was consistent with the hypothesis that the major turning points in the life course for men who refrained from crime and deviance in adulthood were stable employment and good marriages.

Building on our earlier work (Laub and Sampson 1993; Sampson and Laub 1993) and the work of Nagin and Paternoster (1994), we, along with Daniel Nagin, drew an analogy between changes in criminal offending spurred by the formation of social bonds and an investment process (Laub, Nagin, and Sampson 1998). This conceptualization suggests that because investment in social relationships is gradual and cumulative, resulting desistance will be gradual and cumulative. Using a dynamic statistical model developed by Nagin and Land (1993), we tested these ideas about change using yearly longitudinal data from the Gluecks' (1968) study of criminal careers (Laub, Nagin, and Sampson 1998). The results showed that desistance from crime was facilitated by the development of quality marital bonds, and that this influence was gradual and cumulative over time. Thus, the timing and quality of marriage matters: early marriages characterized by social cohesiveness led to a growing preventive effect. The effect of a good marriage takes time to appear, and it grows slowly over time until it inhibits crime.

Another finding from this study was that individual characteristics and family circumstances measured in childhood that are known to predict delinquency and adult criminality have a limited capacity to predict desistance. ${ }^{8}$ That is, conditional on juvenile delinquency, our

\footnotetext{
${ }^{8}$ Similarly, Vaillant and Milofsky (1982) showed that the three childhood variables that most clearly predicted alcoholism failed to predict remission. For comparable findings from a study of narcotic addicts, see Vaillant (1973).
} 
study (Laub, Nagin, and Sampson 1998) found that a host of traditional individual-difference factors were at best weakly predictive of eventual desistance. Nagin, Farrington, and Moffitt (1995) also found that similar background variables had a limited capacity to predict desistance among active offenders in a more contemporary sample of 411 British males born in 1951-54. This line of research further supports the contention that adult social bonds may be important in understanding changes in criminal trajectories.

The idea that desistance from crime is gradual and accompanied by the accumulation of social bonds is supported in research by Horney, Osgood, and Marshall (1995, p. 671). Analyzing month-to-month data over a two- to three-year period for a sample of high-rate convicted felons, Horney, Osgood, and Marshall (1995) showed that large within-individual variations in criminal offending were systematically associated with local life circumstances (e.g., employment and marriage). "Moving in with one's wife doubles the odds of stopping offending (compared to moving away), and moving away from one's wife doubles the odds of starting to offend (compared to moving in)" (Horney, Osgood, and Marshall 1995, p. 665). It is interesting to note that the effect of cohabitation was different-living with a girlfriend was associated with higher rates of offending. As Horney, Osgood, and Marshall (1995) have noted, some of the time, some high-rate offenders enter into circumstances like marriage that provide the potential for informal social control. This confirmation of our marriage results is important because the Horney, Osgood, and Marshall (1995) sample contained a sizable proportion of minorities in a contemporary setting.

Using data from the Cambridge Study in Delinquent Development, Farrington and West (1995) examined the effects of three life eventsgetting married, having a first child, and becoming separated-on offending patterns among working-class males from central London. Part of their analytical strategy was to compare offending before and after marriage within subjects as well as using a more traditional between-subjects analysis. In both the between- and within-subject analyses, Farrington and West (1995) found that marriage decreased offending compared with remaining single. Conversely, separation from a wife and having a child outside of marriage were associated with later offending.

Using data from the National Youth Survey, a longitudinal survey of a nationally representative probability sample of youth in the United States relying on self-reports of criminal involvement, Warr (1998) examined whether desistance from crime was due to marriage or a reduc- 
tion in exposure to delinquent peers that results from marriage. To ensure variability in both rates of marriage and delinquent behavior, data were drawn from waves 5 and 6 , when the respondents were ages fifteen to twenty-one and eighteen to twenty-four, respectively. Warr found that marriage leads to a dramatic decline in time spent with friends as well as reduced exposure to delinquent peers. Warr concluded that his findings provide support for differential association/ social learning theory because peer relations appear to account for the effect of marriage on desistance.

Pezzin (1995) used data from the National Longitudinal Survey of Youth (NLSY) (a nationally representative survey of over 12,000 individuals between fourteen and twenty-two years of age) to investigate the decision to terminate criminal involvement as a function of current and future earnings prospects. She found that the effects of current and future expected criminal earnings significantly reduced the likelihood of offending. Moreover, individuals with higher current legal earnings were more likely to terminate their criminal careers. This study suggests that the benefits of legal behavior need to be considered along with the opportunity costs of illegal behavior in the decision to give up crime.

Shover and Thompson (1992) reanalyzed data from the Rand Inmate Survey in a study of age, differential expectations, and desistance. They outlined two possible explanations of the link between desistance and age. The first was a direct, positive relationship between the aging organism and desistance. The second model emphasized the indirect effects of age on desistance, whereby age interacts with past experiences to alter the assessment of risks and rewards of crime, which in turn leads to desistance from criminal behavior. Shover and Thompson argued that "increasing age and past performance in straight and criminal pursuits determine the offender's differential expectations" (1992, p. 92). Their study revealed support for both the direct and indirect effects of age on desistance from crime.

Selection. Of course, it could be argued that the association between desistance and adult social factors is attributable to a selection process (Gottfredson and Hirschi 1990). A large body of research documents an association between enduring individual characteristics, such as low intelligence and impulsiveness, and criminality. The distribution of these persistent individual differences, which has been referred to as "persistent heterogeneity," is highly skewed to the right (Nagin and Paternoster 1991). It may be that those who desist from crime as 
young adults are in the middle range of the skewed tail: They are sufficiently prone to crime to be delinquent and unattached in their youth, but not so crime-prone to persist in criminal activity and detachment in their adult years. Selection is thus a threat to the interpretation of any desistance study.

Although not experimental in nature, analyses of desistance have addressed this argument in a number of ways. For example, criminal career researchers have explicitly recognized and modeled offender heterogeneity. Blumstein, Farrington, and Moitra (1985) divided the London sample into innocents, persisters, and desisters and estimated the probabilities of offending for each group. Persisters and desisters are present at each stage of arrest, although at each successive arrest the proportion of persisters will increase. These authors applied this approach to the 1945 Philadelphia birth cohort data; data from Lyle Shannon's cohort studies in Racine, Wisconsin; data from Kenneth Polk's cohort studies in Marion County, Oregon; and the London data from the Cambridge Study in Delinquent Development (Blumstein, Farrington, and Moitra 1985, p. 208). Although each of these studies revealed very different prevalence rates, the general pattern of increasing recidivism rates over time was confirmed in each data set. Using the London data, Blumstein, Farrington, and Moitra found seven factors measured at age eight to ten years of age (early conviction, low family income, troublesomeness, poor school attainment, psychomotor clumsiness, low nonverbal IQ, and having a convicted sibling) that discriminated reasonably well between chronic offenders (six or more convictions) and nonchronic offenders (fewer than six convictions) (1985, p. 216).

Many of these enduring individual differences in offender heterogeneity have been explicitly used as controls in analyses attempting to assess the adult predictors of desistance from crime. In our analyses of the Glueck data, for example, the results seem clear that, conditional on a wide variety of individual differences, marriage and labor market experiences predict rates of desistance. We have thus concluded that the process of selection does not account for the association of social bonds and desistance (see especially Sampson and Laub 1993; Laub and Sampson 1993; Laub, Nagin, and Sampson 1998). What happens in the adult life course matters-a conclusion we believe modifies, but does not deny, the importance of childhood factors.

Perhaps the most convincing attempt to counteract selection bias comes from a recent analysis of data from a national work experiment 
that drew participants from poor ghetto areas in nine U.S. cities. Uggen (2000) found that, overall, those given jobs showed no reduction in crime relative to those in a control group. However, age significantly interacted with employment to affect the timing of illegal earnings and arrest. Those age twenty-seven or older were more likely to desist when provided marginal employment. Among those younger, the experimental job treatment had no effect on desistance. This is an important finding because the experimental nature of the data addresses the selectivity that has plagued much research in this area. By specifying event history models accounting for assignment to, eligibility for, and participation in the National Supported Work Demonstration Project, Uggen provides more refined estimates of the effects of work as a turning point in the lives of criminal offenders. ${ }^{9}$ Moreover, the effect of work on facilitating desistance appears to be age graded; that is, marginal work (defined as minimum wage jobs) leads to desistance among those offenders over the age of twenty-six.

Subgroup Differences. Few studies of desistance have examined differential effects by race. Elliott (1994) examined the National Youth Survey data through wave 8 , when the subjects were between ages twenty-four and thirty. Elliott found race differences in desistance over time, with whites desisting earlier than blacks. Elliott speculated that contextual differences-where one was living or workingmight explain these differences.

One of the other unexplored issues in desistance research is gender. Most delinquents are male and desistance appears to result from the formation of social bonds with persons of the opposite sex who are far less likely to be delinquent and deviant. What is the process of desistance for females? We know that the age-crime distribution is virtually identical for males and females, although females commit crime at a much lower rate than males (Gove 1985). Nevertheless, with increasing age, there are sharp drop-offs for both males and females.

Uggen and Kruttschnitt (1998) are among the few researchers to study gender differences in desistance. These authors have argued that not only have the vast majority of studies of desistance involved male samples, but also the legal response to crime has been ignored as well. Uggen and Kruttschnitt developed a theoretical perspective on desistance drawing on rational choice theories, social control theories,

\footnotetext{
${ }^{9}$ Uggen (1999) also found that job quality was related to economic and noneconomic criminal behavior, taking into account sample selection, prior criminality, and other personal characteristics.
} 
and opportunity theories, and they used data from the National Supported Work Demonstration Project to assess patterns of desistance by gender. They found that while women were more likely to desist than men (using both self-report and arrest data), the factors of desistance were the same among men and women. At the same time, they found gender differences in official desistance compared with self-report data (Uggen and Kruttschnitt 1998, p. 361). Unfortunately, there were too few female offenders to disaggregate by crime type. Moreover, this study provides little insight into the underlying mechanisms of desistance by gender.

\section{Qualitative Studies of Offenders and Ex-offenders}

Qualitative studies of offenders and ex-offenders provide another window from which to view the desistance process. Much of this research involves asking detailed, probing questions to subjects, mainly men, who have desisted from crime. This research strategy has been hampered by the use of small, unrepresentative samples, a heavy reliance on retrospective accounts, and an inability to distinguish among competing hypotheses regarding the desistance process. Nevertheless, this line of inquiry has produced important insights into the underlying processes of desistance from crime that are unobtainable from the typical survey.

A common theme in studying offender accounts is that desistance refers to "successful" disengagement from criminal behavior (Meisenhelder 1977). The idea of desistance or "exiting" in this context refers to the subjective experiences of the offender. For example, on the basis of interviews with twenty felons convicted of property offenses, Meisenhelder (1977, p. 325) found that "successful exiting projects include the development of meaningful expressive attachments and behavioral investments that bind the individuals to conformity and that provide them with significant reasons not to deviate." Along similar lines, Irwin (1970) identified three important components of desistance from a criminal career. The first is finding a good job (Irwin 1970, pp. 134$35)$. The second is an "adequate and satisfying relationship with a woman, usually in a family context" (Irwin 1970, p. 203). The third is involvement in extravocational, extradomestic activities such as sports or hobbies (Irwin 1970, p. 203).

Societal reactions to crime also appear to interact with age (Shover 1985, 1996; Gartner and Piliavin 1988, p. 302; Shover and Thompson 1992). For example, Shover (1985) reported that aging interacts with 
the stigma of a criminal record; for those offenders in his sample who desisted in later life, there was an erosion of the original stigma, while for others the process of aging compounded the effect of the original stigma. In this study of fifty aging criminals, Shover (1985) examined two types of experiential change that accompany aging-orientational and interpersonal change. According to Shover, orientational changes included a new perspective on the self, a growing awareness of time changing aspirations and goals, and a growing sense of tiredness. Interpersonal contingencies included the establishment of ties to another person (e.g., a wife) or ties to a line of activity such as a good job (1985, pp. 92-96). Successful participation in a personal relationship, a job, or some other conventional line of activity appeared to reinforce a noncriminal identity.

Recently, Shover (1996) has written one of the most extensive accounts of desistance from crime drawing on qualitative interviews with persistent thieves. As in his earlier work, Shover contended that changes in offending were linked to age and aging, especially the changing calculus of decision making. This process was similar to agerelated changes in the lives of nonoffenders. Variation in criminal careers is associated with objective and subjective career contingencies. According to Shover, two classes of contingencies significantly influenced criminal careers: the development of conventional social bonds, activities, and rewards; and strengthened resolve and determination to abandon crime (1996, p. 124). The first could result from a satisfying relationship with a woman, a religious experience, and a satisfying job. Shover argued that "successful creation of bonds with conventional others and lines of legitimate activity indisputably is the most important contingency that causes men to alter or terminate their criminal careers" (1996, p. 129). Aging also influenced subjective contingencies or what Shover called "orientational, resolve-enhancing contingencies" (1996, p. 130). Men turned away from crime because they were less risky and more rational, gained a new perspective on self, had a growing awareness of time as a diminishing resource, and experienced a change in their aspirations and goals (Shover 1996, p. 131). In addition, Shover's main idea was that the meaning of crime and the calculus of crime changed over the life course. However, Shover painfully noted that many men who desist were successes in "only the narrowest, most bureaucratic meaning of non-recidivism. Most ex-convicts live menial or derelict lives and many die early of alcoholism or drug use, or by suicide" (1996, p. 146). 
Like Shover, Maruna (2001) provides another important focus on subjective orientations in the desistance process in an effort to understand how desistance works. Maruna sought to bring the person back into the picture to supplement the positivist line of research on desistance. Maruna contended that maturation occurred independent of age and led to subjective changes that were essential to sustain desistance from crime. Simply put, people who are going straight-indicating desistance is a process, not an event-undergo a change in personality and self-concept. Thus, phrases like "new person" or a "new outlook on life" apply to those who desist from crime. Using data from life-history narratives for fifty-five men and ten women drawn from a "targeted" and "snowball" sampling frame, Maruna found that reformed offenders were more other-centered and found fulfillment in generative behaviors, felt a greater control over their destiny and took responsibility for shaping their future, and found a "silver lining" in the negative situation resulting from crime and found meaning and purpose in life..$^{10}$ As Maruna (2001) has pointed out, this pattern fits the essential elements of the "prototypical reform story," and this reform tale may be an important part of the desistance process (see also Maruna 1997).

It is noteworthy that Maruna questions the value of the turning point idea to understanding desistance, arguing that it has "probably been overstated" because "nothing inherent in a situation makes it a turning point" (2001, p. 25). For Maruna, a more promising strategy is to focus on individuals as agents of their own change. This view underscores that desistance is a process, not an event, that is initiated by a "disorienting episode" (Lofland 1969) or a "triggering event" (Laub, Nagin, and Sampson 1998) that may or may not lead to a change or turning point in a behavioral trajectory.

Graham and Bowling's (1995) study of desistance had two parts. The first part was an analysis of self-report data drawn from a larger study of offending in England and Wales. The overall sample for this study was over 2,500 individuals ages fourteen to twenty-five. The full sample was used to assess the correlates of persistence and desistance from crime. The second part entailed in-depth life-history interviews with twenty-one desisters (ten males and eleven females, ages sixteen to twenty-seven) to learn more about the influences that led them to de-

\footnotetext{
${ }^{10}$ Employment was not a factor in the desistance process in Maruna's (2001) study. Because of the dire employment situation in Liverpool (the site of his study), only five of the thirty desisting offenders were employed full-time (Maruna 2001).
} 
sist from crime. These subjects were a subsample drawn from the larger project. Desisters were defined as those having committed three offenses in the past (or one serious offense) and self-reporting no new offenses in the twelve-month period prior to the interview. A total of 166 desisters were identified.

For young women, desistance seemed to occur abruptly as they moved into adulthood (e.g., leaving school, leaving home, forming partnerships, and having children). For male offenders, desistance was a more gradual, intermittent process. The social development variables that appeared important for explaining female desisters were far less useful for explaining male desisters. Simply put, males were less likely to make the transition from adolescence to adulthood, and when they did, it had a different effect (or no effect) compared with the effect it had on females. A major component of desistance for men was disengagement from their deviant peers. Graham and Bowling (1995, p. 84) argued that this is a "precondition" for desistance from crime. In addition, male desisters were more likely to live at home and perceive that their schoolwork was above average. From the life-history interviews, along with disassociation with delinquent peers, Graham and Bowling found that changes in identity and maturity were also important. For example, a sense of direction, recognition of the consequences of crime, and learning that crime does not pay were all identified as important factors in interviews with desisters. For women, having children had the greatest influence on desistance, according to interview data.

Mischkowitz (1994) studied desistance with data from the Tubingen Comparative Study of Young Offenders. This is a longitudinal study of 200 males who were incarcerated in prison along with a control group of 200 men the same age drawn from the general population. All of the men were born between 1935 and 1949 and were between the ages of twenty and thirty years at the time of the study. Desistance was defined as having one's last conviction before the age of thirty-one and not being convicted or incarcerated for the last ten years. Fiftytwo case studies of desisters formed the basis of this study. The major finding was that desistance resulted from changes toward a more conventional lifestyle across a variety of domains (e.g., residential, work, family). Although there were different types of desisters (permanent conformists, permanent deviationists, disintegrationists, and reintegrationists), the reintegrationists-those subjects that changed their lifestyle-were the largest group of desisters (Mischkowitz 1994, pp. 321- 
22). The other groups may not offend again but may be involved in "hidden crime"; engage in serious alcohol abuse; or generally lead unproductive, socially isolating, unhappy lives.

To probe further the processes underlying desistance, self-report data were collected on the reasons for desistance from the ex-offenders. These reports were supplemented with social worker reports as to what they saw as the reasons for desistance. It is interesting to note that the subjects thought that "free will" to break with the past was the most important reason, followed by a good marriage, and an interest in an occupational career. Social workers, by contrast, discounted free will and emphasized marriage, jobs, and changing one's milieu. It is important to note that, with respect to personal qualities, social workers mentioned "intelligence and certain skills, occupational ambitions, and sociability and adaptability" (Mischkowitz 1994, p. 325). Like many of the studies reviewed here, religious conversion was not a primary cause of desistance among these fifty-two men.

Baskin and Sommers (1998) conducted in-depth, life-history interviews with 170 women who committed a variety of violent crimes (robbery, assault, and homicide) in New York City. They examined desistance from violent crime for thirty women in their sample. It is not clear how these thirty women were selected or whether they represented the population of desisters among the 170 women. Desistance was defined as no criminal involvement for at least two years prior to the interview. Criminal activity was determined through official arrest record checks as well as interviews with program staff for women who participated in treatment programs. Baskin and Sommers uncovered a number of factors related to the decision to stop offending among their sample of female offenders (e.g., criminal justice sanctions, the pains of imprisonment, isolation from family and friends, and physical and mental "wear and tear" of crime and "living the life" on the street, among others). These same factors were uncovered in Shover's work examining male property crime offenders (see also Cusson and Pinsonneault 1986).

Following Fagan (1989) and Sommers, Baskin, and Fagan (1994), Baskin and Sommers outline a three-step process of desistance (1998, pp. 140-43). The first stage is "forming a commitment to change" (Baskin and Sommers 1998, p. 133). This stage is often triggered by a shock or crisis (see Cusson and Pinsonneault 1986). These catalysts for change may include "socially disjunctive experiences" (e.g., hitting rock bottom) or simply may reflect "delayed deterrence" (Baskin and 
Sommers 1998, p. 141, fig. 6.1). The second stage is called discontinuance. This stage requires a public announcement or "certification" (Meisenhelder 1977, p. 329) that offending will stop. This stage entailed both objective changes (e.g., new social networks) and subjective changes (e.g., new social identity) (see Shover 1996). The women adopted "social avoidance strategies" in the desistance process; separation from persons and places that facilitate continued involvement in crime and drug use (see Graham and Bowling 1995). The third stage of desistance is maintenance of the decision to stop. A key component in stage 3 is building and maintaining a "network of primary relations who accept and support their nondeviant identity" (Baskin and Sommers 1998, p. 136). Thus, new stakes in conformity need to be developed, and the process of identity reformation in turn strengthens these stakes in conformity. From this perspective, desistance is an outcome of a complex, interactional reciprocal process (see also Thornberry 1987).

In one of the only qualitative studies to examine desistance among African-American and Latino American inner-city young men, Hughes (1998) conducted in-depth interviews with twenty subjects who desisted after a long period of criminal activity. Hughes found four significant factors influencing the move of offenders away from antisocial behavior. These factors included respect and concern for children, especially their own children; fear of physical harm, incarceration, or both; contemplation time away from one's immediate environment; and support and modeling from a dedicated person (e.g., a counselor or mentor). Although derived from a small, convenience sample, these findings are generally consistent with the findings from qualitative studies focusing on white men.

\section{Summary}

It is apparent that desistance stems from a variety of complex processes-developmental, psychological, and sociological. In addition, the context in which desistance occurs (or does not occur) seems important in understanding the particular processes of desistance. However, most explanations of desistance have a "post hoc" feel to them. What is not well developed is a coherent framework or theoretical account for explaining desistance. We thus take the next step of formulating the beginnings of a life-course framework to explain desistance from crime. Before we turn to a full discussion of our life-course perspective on desistance, however, it is useful to assess the similarities 
and differences in patterns of desistance from domestic violence, illicit drug use, and alcohol abuse.

\section{Domestic Violence and Other Problem Behaviors}

The question we address here is whether insights into the desistance process can be gleaned by investigating disparate forms of criminal behavior (e.g., domestic violence) as well as other problem behaviors (e.g., drug use and alcohol abuse). Although the evidence is somewhat sketchy, it does appear that domestic violence declines with age (see, e.g., Suitor, Pillemer, and Straus 1990). The evidence is even stronger that drug and alcohol use declines with age (see, e.g., Chen and Kandel 1995). Less is known about the predictors and processes of desistance from domestic violence and other problem behaviors.

\section{A. Domestic Violence}

Conventional wisdom holds that there is little cessation from domestic violence over time. The image is that marital conflict involving physical aggression escalates in frequency and severity of violence. However, studies using nonclinical- or nonshelter-based samples show that while there is some evidence for escalation, there is much more discontinuity in offending patterns, especially minor forms of violence, than expected (see, e.g., Feld and Straus 1989). For instance, using data from the National Youth Survey, Woffordt, Elliott, and Menard (1994) found that a considerable number of offenders (48 percent) "suspended" violence in their marital relationships three years later. In an interesting study using data from a community-based sample, Quigley and Leonard (1996) examined desistance in husband aggression in the first three years of marriage. Desistance was defined as the complete cessation of husband aggression at year 2 and year 3 as reported by both members of the couple. The rate of desistance in this sample was 24 percent. That is, forty-five of the 188 couples that reported husband aggression in the first year of marriage reported no further aggression in year 2 or 3 . Desistance was also associated with better marital and emotional functioning. Those engaging in serious aggression at year 1 were much less likely to desist in years 2 and 3 (14 percent). Thus, there is evidence for desistance in marital violence. The key question is, What are the factors that lead to desistance, and are the processes of desistance the same or different compared with other offenders? ${ }^{11}$

\footnotetext{
${ }^{11}$ One of the major concerns in studies of desistance from domestic violence is sample attrition. It is not known to what extent separation and divorce influences rates of partic-
} 
In a significant essay appearing in an earlier volume of the Crime and fustice series, Fagan (1989) analyzed desistance from family violence. Like many of the works reviewed above, Fagan argued that the causes of onset might not be relevant for understanding desistance. "What is important to the initiation of violence [and other problem behaviors] may be irrelevant to its cessation," wrote Fagan (1989, p. 414). This implies that although problem behaviors (e.g., family violence, substance abuse, and crime) may have different origins, the processes of cessation may be quite similar. For Fagan, desistance is the outcome of processes that begin with aversive experiences leading to a decision to stop offending. In the case of spouse abuse, desistance follows legal sanctions. This suggests an interesting linkage between specific deterrence and desistance that has been generally overlooked in the literature on desistance from crime (but see Paternoster 1989). Fagan distinguishes cessation, remission, and desistance in the context of family violence, but the terms are germane to criminology as a whole. "Desistance refers to a process of reduction in the frequency and severity of family violence, leading to its eventual end when 'true desistance' or 'quitting' occurs" (Fagan 1989, p. 380). For Fagan, desistance implies a "conscious behavioral intent to reduce the incidence of violence" (1989, p. 380), although is it is not clear why "conscious behavioral intent" is necessary in this or any definition of desistance, nor is there any mention whether this concept can even be measured. Cessation refers to "abstention from family violence, either permanent or temporary, often because of legal or other interventions external to the individual [and] remission is a natural process. It describes a temporary state where there is an episodic lull in violent behavior" (Fagan 1989, p. 380). ${ }^{12}$ Although these lulls in offending may become permanent, the notion of remission implies that backsliding is likely (Fagan 1989, p. 380). In his review, Fagan also noted three varieties of cessation: deterrence in response to legal sanctions; dissuasion in response to victim-initiated strategies; and displacement-taking it elsewhere.

ipation in these studies. Research in this area is also hampered by small sample sizes, short follow-up periods, and varying definitions of both domestic violence and desistance.

${ }^{12}$ This is comparable to the intermittency parameter in Nagin and Land (1993). Barnett, Blumstein, and Farrington (1989) developed a model of criminal career patterns among multiple offenders and tested their model prospectively using data up to age thirty for offenders in the Cambridge study of delinquent development. Although their model was generally satisfactory, they did find a small group of offenders who stopped offending and then restarted after a long period of time. 
Fagan's model of desistance from family violence has three distinct stages. Stage 1 entails "building resolve or discovering the motivation to stop." Stage 2 involves "making and publicly disclosing the decision to stop." There must be some catalyst to initiate change. This could be the result of increasing the negative consequences and attendant stigma stemming from acts of family violence (e.g., legal sanctions) or by removing the positive rewards stemming from acts of family violence. Fagan makes the crucial point that the processes that initiate the decision to stop may not be sufficient for desistance to occur (1989, p. 409). Stage 3 entails "maintenance of the new behaviors and integration into new social networks" (Fagan 1989, p. 404). Whether desistance can be maintained without changing social networks and identities is a question for future research. Fagan contends that the "substitution" of new networks and supports for old ones and the "stabilization" of those networks and supports is crucial to the long-term success of desistance.

\section{B. Illicit Drug Use and Alcobol Abuse}

In contrast to research on crime and family violence, there has been some attention devoted to describing the natural history of illicit drug use and alcohol abuse. There is evidence, for example, that most forms of drug use and alcohol abuse decline with age. The exception appears to be cigarette use (see Chen and Kandel 1995). Information is also available regarding the predictors of desistance from illicit drug use and alcohol abuse.

Esbensen and Elliott (1994) used data from eight waves of the National Youth Survey and found that salient life events like marriage and becoming a parent were major factors in discontinuing drug use (i.e., alcohol and marijuana use). Social learning variables that were important in explaining initiation were not significantly related to termination of drug use. However, the relationship between salient life events (e.g., getting married, having a child) may be related to changes in social networks (the number of drug-using friends) (see Warr 1998).

Using a representative sample of over 700 marijuana users, Chen and Kandel (1998) found that the two most important predictors of cessation of marijuana use were frequency of use and age. Infrequent users and those in their late twenties were more likely to stop using. Supporting the notion that life events are important in the cessation of marijuana use, Chen and Kandel (1998) found that first-time pregnancy and parenthood had a significant effect on cessation of marijuana 
use for women but not for men. Getting married did have an inhibitory effect for men, but it appeared to be anticipatory. For example, men were more likely to stop using marijuana one month prior to their marriage, and women were more likely to stop using marijuana nine months before the birth of their first child. Along similar lines, Yamaguchi and Kandel (1985), emphasizing the idea of social role incompatibility, found that in early adulthood marijuana users stopped using after marriage and child bearing. Instability in marital status and employment was related to continued use (see also Kandel and Yamaguchi 1987). Whether these effects are the consequences or determinants of desistance of use of marijuana is debatable, although the evidence appears to be in favor of selection effects (Yamaguchi and Kandel 1985; Kandel and Yamaguchi 1987; Chen and Kandel 1998).

In a study of cessation from cocaine use, White and Bates (1995) found that those who stopped using were more likely to be older, married, and have children. They also found that friends' use of cocaine and negative consequences stemming from using cocaine were most strongly related to cessation. Whether these findings are due to selection effects is not known.

Supporting the idea of negative consequences in cocaine cessation, Waldorf, Reinarman, and Murphy (1991) found that heavy users of cocaine cited health problems (both physical and psychological), financial problems, work problems, and relationship problems as the most important reasons for quitting use. These findings were based on interview data drawn from 106 quitters derived from a snowball sample of present and past cocaine users. In addition to the negative effects of the cocaine experience, a stake in conventional identity and a commitment to conventional life formed the "social-psychological and socialorganizational context within which control and cessation were possible" (Waldorf, Reinarman, and Murphy 1991, p. 222).

In a study of untreated and treated heroin addicts, Biernacki (1986) found that experience of "natural recovery" varied depending on the extent of immersion and identification in the subculture of addiction. Breaking away from the drug and the addict world-both symbolically and literally-is a crucial part of the desistance process. At the same time, addicts need to forge new relationships, new interests, and new investments in order to maintain cessation from drugs. The result of this process is an identity transformation. The course of identity transformation could involve the forging of a new identity, could entail reverting to an old identity that was not spoiled during addiction, or 
could extend an old identity to replace the primacy of the addict identity (Biernacki 1986, pp. 141-60). Biernacki concluded, "A successful transformation of identity requires the availability of identity materials with which the nonaddict identity can be fashioned. Identity materials are those aspects of social settings and relationships (e.g., social roles, vocabularies) that can provide the substance to construct a nonaddict identity and a positive sense of self" $\left(1986\right.$, p. 179). ${ }^{13}$

In a meta-analysis of twenty-seven studies of variations in drinking over the life course, Fillmore and her colleagues (1991) found declines in drinking with age. Temple and his colleagues (1991) found that getting married was negatively associated with consumption for younger and older persons across sex. In contrast, becoming employed was positively related to consumption of alcohol, although the relationship was not significant across all age or sex groups. This study involved a meta-analysis of twelve longitudinal studies. Unfortunately, only two data points were used, and there was no information available on the timing of changes in role status.

In a similar vein, using data from the NLSY, Miller-Tutzauer, Leonard, and Windle (1991) found that young adults who became married exhibited larger decreases of alcohol use compared with those who remained unmarried. Since the declines began in the year prior to marriage, the authors attributed the change to the role transition phase rather than a constraint of marriage itself. As indicated above, whether these declines are due to self-selection (e.g., declines in drinking facilitate marriage) or the effects of courtship and marriage (e.g., alteration in the opportunities to drink) is not clear from this study.

Furthermore, Labouvie (1996), using data from a longitudinal study of two birth cohorts totaling 933 young adults, found evidence for "maturing out" of substance use. Reductions in use were more pronounced for those individuals who became married, became parents, or both, controlling for past use and friends' concurrent use. The benefits of marriage and parenthood appeared the strongest at ages

${ }^{13}$ Adler (1992) has conducted a study of the reintegration of former drug dealers into conventional society. She found that "push" factors were more important than "pull" factors in the desistance process. One of the difficulties former dealers face in the reintegration process is finding legitimate work. Moreover, former dealers find adjustment in the "straight world" particularly difficult because they miss the "level of disposable income, excitement, flexibility, and the pleasure, spontaneity, and freedom they experienced during their halcyon days of drug trafficking" (Adler 1992, p. 124). Adler concludes that her subjects are "postdealers, but not completely reformed deviants" (1992, p. 125; see Adler and Adler 1983). 
twenty-eight to thirty-one, which suggests that the timing of events is important. In addition, declines in use were also associated with perceived decreases in friends' use of alcohol, cigarettes, and illicit drugs, which were more likely to occur after age twenty-five. These findings held for both men and women in the study. Labouvie (1996) concluded that "maturing out" is due to selection and self-correction.

Vaillant (1995) has studied the pathways to abstinence in the context of the natural history of alcoholism. Vaillant (1995) found that recovery was anything but spontaneous. The important factors in fostering desistance from alcohol abuse were new relationships, enhanced hope resulting from increased involvement in religion or Alcoholics Anonymous, supervision and monitoring by formal authorities or informal others such as employers or spouses, and finding a substitute dependency. It is surprising that stable abstinence was not predicted by good premorbid adjustment. In Vaillant's study, sociopaths were as likely to desist from alcohol abuse as those with good mental health. As described in detail in Valliant's 1995 study, data were drawn from two samples-268 former Harvard University undergraduates from the Grant study and 456 nondelinquent controls from the Gluecks' Unraveling 7uvenile Delinquency study.

Little is known about desistance from alcohol abuse without treatment. Using a convenience sample of 182 males, Sobell et al. (1993) found that the majority of "natural recoveries" from drinking problems involved a "cognitive evaluation" of the pros and cons of drinking. Seemingly trivial or mundane events often precipitated changes in drinking behavior. These events seemed to "trigger" a need for change that led to a "major reorientation of the person's frame of reference and perspective" (Sobell et al. 1993, p. 223). Spousal support was reported to be the most helpful factor in maintaining cessation from alcohol abuse.

\section{Summary}

As Fagan (1989) has noted, common processes of desistance have emerged across a variety of problem behavior areas, including crime. First, the decision to stop appears to be preceded by a variety of negative consequences, both formal and informal. Second, multiple processes appear to be involved in sustaining and reinforcing the decision to change. Similarly, examining research on the addictive disorders of alcoholism, smoking, and obesity, Brownell et al. (1986) discovered commonalities in the process of relapse that indicate three basic stages 
of behavior change-motivation and commitment, initial behavior change, and maintenance of change. These authors make the important distinction between lapses (slips) and relapse and argue that much could be learned about the processes of change if we knew which slips lead to relapses and which do not. Information on the timing of lapses in the change process would also be quite helpful. There is some evidence to suggest that the determinants of lapses are different from the determinants of relapses. For instance, lapses are more commonly associated with situational factors, whereas relapses are related to individual factors such as negative emotional states or stress events.

Stall and Biernacki (1986) have examined spontaneous remission with respect to four substances-opiates, alcohol, food/obesity, and tobacco. They identified common processes of spontaneous remission across these four domains. Spontaneous remission is defined as cessation of problematic substance use for one year without formal treatment. What is compelling about this topic is that these substances are generally considered "addictive." Although the data are limited, key factors in the cessation process included health problems, social sanctions, significant others, financial problems, significant accidents, management of cravings, positive reinforcements for quitting, internal psychic change or motivation, and change in lifestyle. Like others, Stall and Biernacki (1986) propose a three-stage model of spontaneous remission behavior. The first stage concerns building resolve or motivation to quit. The second stage involves a public pronouncement to quit problematic substance use. The third stage is the maintenance of the resolution to quit the problem behavior. This includes the acceptance of a new identity as a nonuser, support from significant others, and successful integration into new, nonusing social networks.

Finally, Prochaska, DiClemente, and Norcross have concluded that the processes of change across a variety of life domains (addictive and other problem behaviors) reveal "robust commonalities in how people modify their behavior. From our perspective, the underlying structure of change is neither technique-oriented nor problem specific" (1992, p. 1110). Prochaska and Velicer (1997) propose what they call a "transtheoretical model" that posits that behavior change occurs through six specific stages of change-precontemplation, contemplation, preparation, action, maintenance, and termination. These stages of change were found across twelve different health behaviors, and they help us to understand "when particular shifts in attitudes, intentions, and behaviors occur" (Prochaska, DiClemente, and Norcross 1992, p. 1107). 
In addition to the stages of changes, Prochaska and Velicer (1997) identified a common set of processes of change that also occur across a wide range of health behaviors. These processes of change can be generally characterized as two factors-experiential processes (e.g., self-reevaluation) and behavioral processes (e.g., helping relationships). The processes of change allow us to understand how these shifts occur. The prospects for change are most likely when there is a successful integration of the stages and processes of change. Like Brownell et al. (1986), Prochaska, DiClemente, and Norcross (1992) argue that because relapse is expected, a spiral pattern (rather than linear progression) best captures how people move through the stages of change.

In short, there appear to be commonalities when desisting from several behaviors, including those thought to be addictive. What is striking is that the processes of desistance from problem behaviors such as alcohol dependency are quite similar to the processes of desistance from predatory crime. The significant elements to date are the decision or motivation to change, cognitive restructuring, coping skills, continued monitoring, social support, and general lifestyle change, especially new social networks.

\section{Frameworks for Understanding the Desistance Process}

We believe that there are several theoretical accounts of desistance that can provide a framework for classifying and interpreting the individual studies we reviewed above. While there is overlap across these frameworks, we highlight what we see as the differing elements of emphasis within each particular framework. All of these accounts point to promising leads in the desistance process. At the same time, none of the accounts are fully satisfying, and in the end they raise more questions than they answer. We review each of these frameworks and then conclude that the life-course framework is the most promising approach for advancing the state of knowledge regarding desistance from crime and other problem behavior.

\section{A. Maturation and Aging Accounts of Desistance}

Framework I. The Gluecks developed the idea of maturation as the key factor in explaining desistance from crime. Their theory was that "the physical and mental changes which enter into the natural process of maturation offer a chief explanation of improvement of conduct with the passing of years" (Glueck and Glueck 1974, p. 149). Desistance 
occurred with the passage of time, specifically, there was a "decline in recidivism during the late twenties and early thirties" (Glueck and Glueck 1974, p. 175). ${ }^{14}$ Thus, for the Gluecks desistance was normative and expected, unless an offender had serious biological and environmental deficits (Glueck and Glueck 1943). At the same time, the Gluecks argued that persistent recidivism could be explained by a lack of maturity; offenders who eventually desisted experienced delayed or belated maturation. Although perhaps tautological in nature, the Gluecks argued that the men under study "finally achieved enough integration and stability to make their intelligence and emotionalvolitional equipment effective in convincing them that crime does not lead to satisfaction and in enhancing their capacity for self-control" (Glueck and Glueck 1974, p. 170).

The Gluecks believed that maturation was a complex concept and process. They wrote that maturation "embraces the development of a stage of physical, intellectual, and affective capacity and stability, and a sufficient degree of integration of all major constituents of temperament, personality and intelligence to be adequate to the demands and restrictions of life in organized society" (Glueck and Glueck 1974, p. 170). The Gluecks were quite clear that desistance "cannot be attributed to external environmental transformations" (1974, p. 173). The Gluecks called for more research into the "striking maturation" phenomenon from biological, psychological, and sociological perspectives with the goal to "dissect maturation into its components" (1940, p. 270). It is interesting that for the Gluecks age and maturation were not one and the same. It was the case that as age increased, recidivism declined. But age alone was not enough to explain maturation. "It was not the achievement of any particular age, but rather the achievement of adequate maturation regardless of the chronological age at which it occurred that was the significant influence in the behavior change of our criminals" (Glueck and Glueck 1945, p. 81). Nonetheless, the basic idea of this approach is that desistance is the result of offenders growing out of crime and settling down.

Framework II. A variation of the Gluecks' approach is found in Gottfredson and Hirschi's A General Theory of Crime (1990). Like the Gluecks, Gottfredson and Hirschi argue that crime declines with age

\footnotetext{
${ }^{14}$ One idea offered by the Gluecks that has not been supported is that regardless of the age of onset, crime and delinquency run a "fairly steady and predictable course" (Glueck and Glueck 1974, p. 150). Most research shows early onset is linked to a longer criminal career.
} 
for all offenders (see also Hirschi and Gottfredson 1983). Gottfredson and Hirschi contend that the age distribution of crime-onset, frequency, and desistance-is invariant across time, space, and historical context and that this relationship cannot be explained by any variables available in criminology. Gottfredson and Hirschi state, "This explanation suggests that maturational reform is just that, change in behavior that comes with maturation; it suggests that spontaneous desistance is just that, change in behavior that cannot be explained and change that occurs regardless of what else happens" (1990, p. 136).

A fundamental aspect of the Gottfredson and Hirschi account of desistance is the distinction between crime and criminality (1990). According to Gottfredson and Hirschi, crimes are short-term, circumscribed events that presuppose a set of conditions. In contrast, criminality refers to relatively stable differences across individuals in the propensity to commit crime. Gottfredson and Hirschi go on to argue that while crime everywhere declines with age, criminalitydifferences in propensities, like self-control-remains relatively stable over the life course. They write, "Desistance theory asserts that crime declines with age because of factors associated with age that reduce or change the criminality of the actor. The age theory asserts that crime, independent of criminality, declines with age" (Gottfredson and Hirschi 1990, p. 137). For Gottfredson and Hirschi, criminality is impervious to institutional involvement and impact.

Unlike the Gluecks, Gottfredson and Hirschi do not invoke the process of maturation but rather see a direct effect of age on crime. Decreases in offending over time are "due to the inexorable aging of the organism" (Gottfredson and Hirschi 1990, p. 141). From this theoretical perspective, it follows that criminal behavior is largely unaffected by life-course events-marriage, employment, education, and so forth-or any situational or institutional influences. The basic idea is that desistance "just happens" and that the age effect cannot be explained with the available terms and concepts. ${ }^{15}$

\section{B. Developmental Accounts of Desistance}

Framework I. The first developmental account of desistance we present focuses on change in objective and subjective contingencies that accompany aging (Neugarten 1996). For example, identity changes

${ }^{15}$ In a variation of the Gottfredson and Hirschi (1990) position, Wilson and Herrnstein contend that aging leads to a lowering of propensity for crime (1985, p. 145). Both support the notion that declines in crime over the life span are due to aging. 
may account for reductions and cessation in crime (see Maruna 2001; see also Gartner and Piliavin 1988; Shover 1996). To illustrate, Mulvey and LaRosa (1986) focus on the period from age seventeen to twenty, the period they call the time of natural recovery. They argue that desistance is the result of shifts in behavioral patterns that characterize adolescence, especially late adolescence (see Mulvey and Aber [1988] for details on this developmental perspective).${ }^{16}$ This process is similar to the one uncovered by Shover in his study of behavioral shifts in response to aging among men.

This account of desistance suggests two themes. First, desistance is normative and expected across the life span. Some "rough-andtumble" toddlers will desist from antisocial behavior as they enter school, some adolescent delinquents will desist while in high school, and some older delinquents will desist as they make the transition to young adulthood, and so on. Second, cognitive change is a precursor to behavioral change. What Maruna (2001) calls "identity deconstruction" is necessary to begin the long-term process of desistance. ${ }^{17}$

Framework II. A second developmental account of desistance is offered by Gove (1985). Gove argues that explanations of the cessation of various forms of crime and deviance must incorporate biological, psychological, and sociological variables. Thus, Gove seeks to merge elements of both ontogenetic and sociogenic models. Like Hirschi and Gottfredson (1983), Gove maintains that sociological theories of crime are unable to explain patterns of desistance revealed in the data. Gove reviewed six theories of deviance-labeling theory, conflict theory, differential association theory, control theory, anomie theory, and functional theory-and concluded that "all of these theoretical perspectives either explicitly or implicitly suggest that deviant behavior is an amplifying process leading to further and more serious deviance" (1985,

${ }^{16}$ In a series of interviews with delinquent youth, Mulvey and Aber (1988) found that fear of adult sanctions was not an important factor in explaining desistance (but see Glassner et al. [1983] for the opposite finding). However, Mulvey and Aber (1988) did find that youths' social competence in taking advantage of opportunities to "straighten out" was an important, but overlooked, element in the desistance process.

${ }^{17}$ This raises a thorny methodological point. As Gartner and Piliavin have noted, "when an event such as taking a job, marrying, or having a child occurs prior to desistance from crime, it may be viewed as a sign of orientational change. The orientational change, rather than the event itself, is seen as the true cause of desistance. It may be, however, that the event limits the opportunities, time, and energy available for crime even while subjective motivations remain constant, and that objective constraints are directly responsible for changes in behavior" $(1988$, p. 302). There is currently no way to disentangle the role of subjective vs. objective change as the cause of desistance. It is probably the case that both are present in the change process. 
p. 118). However, changes in socially structured roles, psychological well-being, psychological maturation, and biological factors such as physical strength, physical energy, psychological drive, and the need for stimulation provide reasonable accounts of desistance from crime with age. Gove concludes that "biological and psychological factors appear to play a critical role in the termination of deviant behavior" (1985, p. 136). The peak and decline in physical strength, energy, psychological drive, and the need for stimulation maps fairly well the peak and decline in deviant behavior.

Framework III. A third developmental account of crime and desistance from crime is offered by Moffitt (1994). Moffitt spells out two distinct categories of individuals, each possessing a unique natural history of antisocial behavior over the life course. From a desistance standpoint, what is important is that these two antisocial trajectories have unique etiologies that in part account for the differences in desistance.

Life-course-persistent offenders start early in childhood and persist in offending well into adulthood. For this small group of offenders, neuropsychological deficits in conjunction with disrupted attachment relationships and academic failure drive long-term antisocial behaviors. Thus, life-course-persistent offenders do not desist from crime. As Moffitt states, it is not the traits or the environment per se that account for continuity. Rather, her theory of continuous antisocial behavior (and by definition, no desistance) "emphasizes the constant process of reciprocal interaction between personal traits and environmental reactions to them" (Moffitt 1994, p. 28). Antisocial dispositions infiltrate into all domains of adolescence and adulthood, and this "diminishes the likelihood of change" (Moffitt 1994, p. 28).

The adolescence-limited offenders are involved in antisocial behavior only during adolescence. This large group of offenders has no history of antisocial behavior in childhood. The delinquency of the adolescence-limited group is situational, and, as a result, virtually all of these offenders desist from criminal behavior over time. Adolescencelimited offenders seek to enjoy the spoils of adulthood (what Moffitt calls the maturity gap), and they mimic the antisocial styles of lifecourse persisters, and, in turn, they are socially reinforced by the "negative consequences" of delinquent behavior (Moffitt 1994, pp. 30-33). Adolescence-limited offenders desist from crime in response to changing contingencies and reinforcements. For the adolescence-limited group, desistance, like delinquency, is normative. Because adolescence- 
limited offenders have no history of childhood antisocial behavior resulting in large part because of neuropsychological deficits, the forces of cumulative continuity are much weaker for this group of offenders. Simultaneously, adolescence-limited offenders have more prosocial skills, more academic achievement, and stronger attachments than their life-course-persistent counterparts, characteristics that facilitate desistance from crime.

In sum, Moffitt argues that "the age of desistance from criminal offending will be a function of age of onset of antisocial behavior, mastery of conventional prosocial skills, and the number and severity of 'snares' encountered during the foray into delinquency. Snares are consequences of crime, such as incarceration or injury, that constrain conventional behavior" (Moffitt 1994, p. 45). "Adolescence-Limited delinquents can profit from opportunities for desistance, because they retain the option of successfully resuming a conventional lifestyle. Life-Course-Persistent delinquents may make transitions into marriage or work, but their injurious childhoods make it less likely that they can leave their past selves behind" (Moffitt 1994, p. 45). In contrast to our work (Sampson and Laub [1993], discussed below), Moffitt sees life-course events as conditional determinants of desistance. ${ }^{18}$

\section{A Life-Course Account of Desistance}

Applying the life-course framework to the study of desistance leads to a focus on continuity and change in criminal behavior over time, especially its embeddedness in historical and other contextual features of social life. The starting point for this account is the large withinindividual variations in antisocial behavior over time. Antisocial behavior appears to be highly stable and consistent only for a relatively small number of males whose behavior problems are quite extreme. Even Moffitt (1994) builds on this information to argue that stability is a trait only among "life-course-persistent" delinquents. Whereas change is the norm for the majority of adolescents, stability characterizes those at the extremes of the antisocial-conduct distribution.

In support of this idea, recent criminological research suggests that

${ }^{18}$ Cohen and Vila (1996) have made a similar argument with respect to the different categories of chronic offenders. At one end of the continuum of high rate offenders are "sociopaths." At the other end of the continuum are "competitively disadvantaged" offenders (Cohen and Vila 1996, pp. 144-47). See also Nagin and Land (1993) and D'Unger et al. (1998) for more discussion of typologies of criminal offending over time. The implication is that not all offenders will desist and the processes of desistance may be unique to each distinct offender category. 
salient life events influence behavior and modify trajectories-a key thesis of the life-course framework. Specifically, in our earlier work (Sampson and Laub 1993), we have argued that changes in crime (desistance) are due to variations in informal social control or social bonds that are independent of age. Thus, like the developmental accounts of cessation of offending, we maintain that other factors besides age influence the desistance process. The key point here is that salient life events in the life course may or may not change criminal trajectories. What is important is how these salient life events-work, marriage, and military-affect social bonds and informal social control. It may be that crime, criminality, and opportunities for crime vary in response to changes in informal social control. Regardless of the exact reasons for the change, we contend that life-course events matter in the onset, continuation, and desistance process. That is, the life-course events help explain stability and change in behavior over time (see also Rutter, Quinton, and Hill 1990; Thornberry 1987, pp. 881-82).

Despite their similarity, we wish to distinguish the life-course framework from developmental perspectives on crime and desistance. Developmental accounts flow mainly from psychology and focus on regular or lawlike individual development over the life span. Implicit in developmental approaches are the notions of stages, progressions, growth, and evolution (Lewontin 2000). Thus, the resulting emphasis is on systematic pathways of development over time, with the imagery being of the execution of a program written at an earlier point in time. In contrast, life-course approaches, while incorporating notions of individual development such as aging, emphasize variability and exogenous influences on the course of development over time that cannot be predicted by focusing solely on enduring individual traits or even past experiences. Flowing mainly from sociology, life-course accounts embrace the notion that lives are often unpredictable and dynamic and that exogenous changes are ever present. Some changes in life course result from chance or random events, while other changes stem from macrolevel "exogenous shocks" largely beyond the pale of individual choice (e.g., war, depression, natural disasters, revolutions, plant closings, industrial restructuring). Another important aspect of life-course criminology is a focus on situations-time-varying social contextsthat impede or facilitate criminal events. But the bottom-line difference from developmental (especially psychological) accounts is the theoretical commitment to the idea of social malleability across the life 
course and the focus on the constancy of change, including the dynamic processes that serve to reproduce stability.

\section{Rational Choice Accounts of Desistance}

The main idea of the rational choice framework of desistance is that the decision to give up crime is based on a conscious reappraisal of the costs and benefits of crime (see Clarke and Cornish 1985; Cornish and Clarke 1986; Gartner and Piliavin 1988). In this perspective, the desisters, like the persisters, are seen as "reasoning decisionmakers" (Cornish and Clarke 1986, p. 13). One important component of this decision is the increasing fear of punishment with aging (see also Cromwell, Olson, and Avary 1991). However, aging is not necessarily tied to the decision to give up crime.

Some researchers have tried to understand the context of rational decisions to stop offending. For example, Cusson and Pinsonneault (1986) contend that the decision to give up crime is triggered by a "shock" of some sort (e.g., a shoot-out during a crime) or "delayed deterrence" (e.g., increased fear of doing more time) or both. Cusson and Pinsonneault found the decision to give up crime was "voluntary and autonomous" (1986, p. 78). These findings are highly speculative-as conceded by the authors-since the study was based primarily on interviews with seventeen ex-robbers in Canada. In a similar vein, Leibrich (1996) studied thirty-seven men and women in New Zealand who were on probation and in the process of going straight. She found that shame was the primary factor in the desistance process in that it was the most commonly identified cost of offending. Three kinds of shame were reported: public humiliation, personal disgrace, and private remorse. As Leibrich stated, "shame was the thing which most often dissuaded people from offending and the growth of self-respect was the thing which most often persuaded them to go straight" (1996, p. 297).

In an interesting study, Paternoster (1989) integrated deterrence and rational choice perspectives in an attempt to understand decisions to participate in and desist from delinquency (i.e., marijuana use, drinking liquor, petty theft, and vandalism). Drawing on data from 1,250 high school students surveyed at three times, Paternoster found that the decision to desist was not related to formal sanction threats (e.g., the perceived severity and certainty of punishment). However, in support of a rational choice perspective, decisions to desist were related to 
changes in moral tolerance of the delinquent act. Those offenders who made a decision to stop offending began to have stronger moral reservations about the illegal acts in question. This finding held for all four delinquent offenses. It is noteworthy that changes in moral beliefs were associated with changes in peer involvement.

\section{E. Social Learning Accounts of Desistance}

Social learning frameworks have been offered to provide explanations of desistance from crime and other forms of problem behavior. Akers (1990) has forcefully argued that social learning accounts incorporate all of the major elements of rational choice and deterrence frameworks. One of the strengths of the social learning approach is its application to all crime types as well as illicit drug use, alcohol abuse, and other problem behaviors (see Akers [1998] for an extensive review of the research literature). In the social learning framework, the basic variables that explain initiation into crime are the same variables that account for cessation from crime. Therefore, for the most part, the account of desistance is the account of initiation in reverse. For example, differential association with noncriminal friends and significant others, less exposure to or opportunities to model or imitate criminal behavior, developing definitions and attitudes favorable to conformity and abiding by the law, and differential reinforcement (social and nonsocial) discouraging continued involvement in crime are all part of the desistance story. Imitation appears less important after onset, while social and nonsocial reinforcements become more important (see Akers 1998). As for onset and continuation, the most important factor in desistance is peer associations.

In support of the social learning framework, Warr (1993) presented data that showed differential association can account for the decline in crime with age. Using data from the first five waves of the National Youth Survey for respondents ages eleven to twenty-one, Warr (1993) found that peer associations (e.g., exposure to delinquent peers, time spent with peers, and loyalty to peers) changed dramatically with age. With respect to desistance, declines in crime were linked with declines in peer associations. When peer variables were controlled, "the association between age and crime is substantially weakened and, for some offenses, disappears entirely" (Warr 1993, p. 35).

Warr (1998) also contended that reduced exposure to delinquent peers accounts for the association between marital status and delinquent behavior. For Warr, marriage is important in desistance from 
crime because marriage reduces, weakens, and severs ties with delinquent associates. What is not established in Warr's analysis is the mechanism explaining desistance from crime. For instance, an alternative explanation for desistance of crime resulting from marriage focuses on changes in routine activities and opportunities for crime and deviance. Marriage changes one's routine activities, especially with regard to leisure time activities. With Warr's analysis, as with our own (Sampson and Laub 1993), there is no way to distinguish between differential association and routine activity or opportunity explanations of the marriage effect. It is also possible that social control theory can account for Warr's findings. It may well be that friendships change as the result of spouses exerting social control on their mates. For example, wives may limit the husband's number of nights out with the guys. Also, it is possible for new friends to replace old friends as the result of marriage. Marriage often leads to a residential move and exposure to new friends and family. These friends and family can exert social control as well.

\section{F. Summary}

According to Elder (1998), the life-course perspective contains several principles: a focus on historical time and place that recognizes that lives are embedded and shaped by context; the recognition that the developmental effects of life events are contingent on when they occur in a person's life-that is, timing matters; the acknowledgment of intergenerational transmission of social patterns-the notion of linked lives and interdependency; and the view that human agency plays a key role in choice making and constructing one's life course. In short, the major objective of the life-course perspective is to link social history and social structure to the unfolding of human lives. A life-course perspective thus looks to explain variations in crime within individuals over time, regardless of whether one is interested in understanding persistence or desistance. Moreover, the life-course perspective is compatible with several criminological theories-social control, social learning, and rational choice. Consistent with this dynamic perspective, an integrative approach to the study of desistance was recently offered by Farrall and Bowling (1999). Arguing that the literature is polarized along the agency-structure divide, these authors seek to integrate structuration and human development theories and thus examine individual decisions, structural constraints, and life events as they lead to change in behavior.

In the next section, we draw on the life-course framework to dis- 
tinguish the event of terminating offending behavior from the process of desistance from crime. Our framework focuses on the structural sources of change and their role in the process of desistance from crime. The idea of "turning points" frames our discussion. Furthermore, we emphasize the interaction of human agency, life-course events, and context in this process.

\section{A Life-Course Framework for Understanding Desistance}

In this section we draw on material from our forthcoming book, Boys in Trouble and How They Age (Laub and Sampson 2001). In this book, we present and analyze newly collected data on crime and development from birth to age seventy among a group of 500 men with troubled backgrounds. Remanded to reform schools in Massachusetts during their adolescence, these 500 men were the original subjects of a classic study by Sheldon and Eleanor Glueck (1950). Followed to age thirtytwo by the Gluecks (Glueck and Glueck 1968) and also studied in our previous work (Sampson and Laub 1993), these men's early lives are known to us in unusual detail.

Our book updates these men's lives at the close of the twentieth century. We tracked, located, and conducted personal life-history interviews with fifty-two men as they approached age seventy. Cases were selected on the basis of their trajectories of adult offending (e.g., persisters, desisters, and intermittent offenders). Overall, fourteen of the men we interviewed were persistent offenders, nineteen were classified as desisters, and nineteen displayed patterns of intermittent offending. The fifty-two life-history interviews were combined with our collection of criminal histories and death records for all 500 original delinquents to age seventy. Integrating these diverse data on lives over seven decades, we present a theory of crime that unites the simultaneous unfolding of personal choice, situational context, and social control. By emphasizing within-individual patterns of variability across the full life course, we illuminate the natural history of crime and its control. We present some illustrative findings from our in-depth, life-history narratives for the group of the men who desisted from crime.

From our analysis it appears that offenders desist as a result of a combination of individual actions (choice) in conjunction with situational contexts and structural influences linked to important institutions. This fundamental theme underscores the need to examine individual motivation and the social context in which individuals are 
embedded. The processes of desistance operate simultaneously at different levels (individual, situational, and community) and across different contextual environments (family, work, and military). The process of desistance is more than mere aging or "maturational reform" (Matza 1964), and we believe that life-history narratives are useful for unpacking complex interactions between individuals and their environments.

The idea of "turning points" is one way of thinking about change processes. Abbott contends that "turning points are narrative concepts, referring to two points in time at once" $(1997$, p. 85$)$. Turning points are often retrospective constructions, but Abbott claims that they do not have to be. Abbott identifies several types of turning points-focal, randomizing, and contingent $(1997$, p. 94) - but all turning points are "shifts that redirect a process" (1997, p. 101). In a similar vein, Denzin emphasizes "epiphanies," and these are defined as a "moment of problematic experience that illuminates personal character, and often signifies a turning point in a person's life" $(1989$, p. 141). Like Abbott, Denzin identifies several types of epiphanies-major, cumulative, illuminative, and relived (see Denzin 1989, pp. 129-31). Turning points and epiphanies are implicated in the desistance process and reveal the interactive nature of human agency and life events such as marriage, work, and serving in the military. Of course, these individual-level processes take place in a larger structural context. Group processes and structural determinants (e.g., race and ethnicity, social class, and neighborhood) also need to be considered in the desistance process (see also Sullivan 1989).

It thus appears that successful cessation from crime occurs when the proximate causes of crime are affected. A central element in the desistance process is the "knifing off" of individual offenders from their immediate environment and offering them a new script for the future (Caspi and Moffitt 1995). Institutions like the military have this knifing-off potential, as does marriage, although the knifing-off effect of marriage may not be as dramatic.

Another component in the desistance process is the "structured role stability" that emerges across various life domains (e.g., marriage, work, residences). The men who desisted from crime shared a daily routine that provided both structure and meaningful activity. The structure was fully embraced by the men, and one result was a disassociation from delinquent peers in adulthood, a major factor in explaining their desistance from crime (see Graham and Bowling 1995; 
Warr 1998). Osgood et al. (1996) have shown that participation in unstructured socializing activities with peers increased the frequency of deviant behaviors among those ages eighteen to twenty-six. Marriage has the potential to radically change routine activities, especially with regard to one's peer group. As Osgood and Lee (1993) argued, marriage entails obligations that tend to reduce leisure activities outside of the family. It is reasonable to assume that married people will spend more time together than with their same-sex peers. Marriage, therefore, has the potential to cut off an ex-offender from his delinquent peer group (see Warr 1998).

The routine activities of work and family life and the resulting informal social ties have two functions. One is to provide social support (Cullen 1994) or emotional "attachment" (Hirschi 1969). The other function is monitoring and control by providing a set of activities and obligations that often are repeated each day. Many habits are mundane, but they nonetheless give structure to one's time and restrict opportunities for crime. Moreover, these activities result from shifts in role expectations that are not fully explained by age (Osgood and Lee 1993).

What is also notable in the desistance process is human agency. A vital feature that emerged from our qualitative data is that personal conceptions about the past and future are apparently transformed as men maneuver through the transition from adolescence to adulthood (Emirbayer and Mische 1998, p. 992; see also Cohler 1982; Maruna 2001). The men engage in what can be called "transformative action." Although informed by the past, agency is also oriented toward the future (see Emirbayer and Mische 1998; Maruna 2001). Thus, projective actions in the transition from adolescence to adulthood advance a new sense of self and a new identity as a desister from crime or, more aptly, as a family man, hard worker, good provider, and so forth. Thus, the men we studied were "active" participants in the desistance process. ${ }^{19}$

As we observed in our life-history narratives, the men who desisted from crime seem to have acquired a degree of maturity by taking on family and work responsibilities. They forged new commitments, made a fresh start, and found new direction and meaning in life. These com-

${ }^{19}$ Using detailed narrative data from a follow-up study of a sample of adolescent female and male offenders, Giordano, Cernkovich, and Rudolf (2000) find a reciprocal relationship between the actors' own cognition and their subsequent behavior. In this study, human agency is an important element in the desistance process for both female and male offenders. (For more details, see Giordano, Cernkovich, and Rudolph [2000].) 
mitments were not necessarily made consciously or deliberately but rather were "by default" — the result of "side bets" (Becker 1960, p. 38). The men made a commitment to go straight without even realizing it. Before they knew it, they had invested so much in a marriage or a job that they did not want to risk losing their investment (Becker 1960). Involvement in these institutions-work and marriage-reorders short-term situational inducements to crime and, over time, redirects long-term commitments to conformity (Briar and Piliavin 1965).

It seems that men who desisted changed their identity as well, and this in turn affected their outlook and sense of maturity and responsibility. From our life-history narratives, for example, we sense that certain roles and certain behaviors are seen as "age inappropriate" (see also Hill 1971; Shover 1996). One former delinquent linked the role of "party boy" to being young and single. In response to the question, "What about your marriage? Has that changed you?" Richard said with a hearty laugh, "Oh yeah. I mean that's when you really had to settle down." He continued, "Especially when John [his oldest son] came." Remaining a delinquent or a party boy or a hell-raiser would signify a state of "arrested development" and be incompatible with an adult status (see Gove 1985, p. 129). This notion is consistent with Hill (1971), who discussed changes in identity over the life cycle as one moves from "a hell-raiser to a family man."

We are by no means claiming an absence of regret in the process of desistance. In his study of the transformation from being a hell-raiser to being a family man, Hill presented evidence of the ambivalence that men sense regarding their new role and identity as "family men" (1971). This is not surprising because, as Smelser pointed out, bonded relations are fused with ambivalence-dependence, even when welcomed, "entails a certain entrapment" (1998, p. 8). For example, William told us that if he were not married he would be "wandering" around. He said ruefully, "There's many times I wanted to go back to Alaska to see what it was like now. But we can't do that. We're hoping to go to Disney next March." We heard many such bittersweet remembrances of deviant lives left behind-of exciting moments given up.

Thus, both objective and subjective contingencies are important in the desistance process (Shover 1996). Cohler (1982) noted that a subjective reconstruction of the self is especially likely at times of transition. The basic idea relates to "the double constitution of agency and structure: temporal-relational contexts support particular agentic orientations, which in turn constitute different structuring relationships 
of actors toward their environments. It is the constitution of such orientations within particular structural contexts that gives form to effort and allows actors to assume greater or lesser degrees of transformative leverage in relation to the structuring contexts of action" (Emirbayer and Mische 1998, p. 1004).

The lessons we learned about desistance from our life-history narratives are consistent with the research literature on drug and alcohol relapse. In a study of 100 hospital-treated heroin addicts and 100 hospital-treated alcohol-dependent individuals, Vaillant (1988) found that external interventions that restructure a drug addict's or an alcoholic's life in the community were often associated with sustained abstinence. The main factors are compulsory supervision, finding a substitute dependence to compete with drug or alcohol consumption, obtaining new social supports, and membership in an inspirational group and discovery of a sustained source of hope and inspiration (see also Vaillant and Milofsky 1982). Culling the recent literature on treatment, especially from Canada, produces some hopeful signs that offenders can be rehabilitated when proximate causes of crime are targeted. Programs that address dynamic attributes of offenders and their circumstances (e.g., antisocial attitudes, involvement with delinquent peers, and employment status) that can change during and after the treatment process appear to be more successful than programs that focus on static factors or background characteristics (Andrews, Bonta, and Hoge 1990; Andrews and Bonta 1994; Gendreau, Cullen, and Bonta 1994; Bonta 1996; Gendreau 1996).

What is also striking from our life-history narratives is that there appear to be no major differences in the process of desistance for nonviolent and violent juvenile offenders. Despite contrary expectations from many criminological theories, this finding is consistent with empirical research showing that violent offenders have the same background characteristics as frequent but nonviolent offenders (Farrington 1991; Capaldi and Patterson 1996; Piquero 2000). In fact, Farrington concluded that "the causes of aggression and violence must be essentially the same as the causes of persistent and extreme antisocial, delinquent, and criminal behavior" (1991, p. 25). Our life-history narratives reveal that the processes of desistance across a wide variety of crime types are very similar.

Of course, an important caveat in our research concerns what we have called the "favored historical context" in which the Glueck men came of age. This period of history was marked by less alienation and 
social deviance than today, low unemployment, increasing national wealth, and expansion of the occupational structure. In contrast, the level of training and education required for most employment today has changed dramatically. In this context, William Julius Wilson (1996) has documented the decline of work, especially in disadvantaged neighborhoods in U.S. cities. As noted by Wilson and others, the consequences of joblessness are severe with respect to a variety of outcomes, including crime, family life, and community organization.

One other important aspect of the historical context for this cohort concerns the military. Military service in the World War II era provided American men from economically disadvantaged backgrounds with an unprecedented opportunity to better their lives through onthe-job training and further education, especially the G.I. Bill of Rights (see Sampson and Laub 1996). In contrast, the military as a vehicle for escaping poverty has stalled in the 1990s for persons disadvantaged economically and socially (e.g., high school dropouts, members of minority groups, young people with criminal records). There is evidence that nearly half of those who try to join today's military do not get in and that the military has virtually abandoned recruiting in disadvantaged neighborhoods in inner cities (Ricks 1997).

\section{Directions for Theory, Research, and Policy}

What are the implications of our review for future theory, research, and policy? Although there is a developing body of research in this area, there is still much to learn, especially regarding the causal mechanisms in the desistance process. Combining our review with our newer work on desistance from crime, we conclude with an agenda that is broad based yet focused on targeted areas that we believe are most promising.

\section{A. Theoretical Considerations}

Several theoretical considerations are worth emphasizing at the outset. First, questions about the processes of desistance must be linked to a theory of crime. Because studies of desistance are also studies of persistent and intermittent offending, we need more theoretical consideration of the natural history of crime.

Second, our understanding of desistance has been hampered by the lack of long-term studies, especially of those involved with the criminal justice system and other systems of formal social control. What we have are "short-term snapshots" and these need to be replaced by 
"long-term patterns" that convey the dynamic interplay between behavior and temporal variables.

Third, dichotomies such as desister/persister should be used only as heuristic devices. There is substantial heterogeneity in offending patterns-dichotomies (like means) ignore too much variation and have the potential to reify arbitrary groupings. Failing to recognize the inherent artificiality of groups and arbitrary constructions of the "offender" threaten to undermine the program of desistance research altogether. To our mind, the most fruitful desistance theory will focus on the causes of variability in within-individual offending patterns. Following Daniel Glaser, we underscore a theoretical appreciation for the concept of a zigzag path. "Criminals go from noncrime to crime and to noncrime again. Sometimes this sequence is repeated many times, but sometimes criminals clearly go to crime only once; sometimes these shifts are for long durations or even permanent, and sometimes they are short-lived" (Glaser 1969, p. 58). We thus believe that theory should focus not on arbitrary designations between individuals but on what accounts for the variation in offending trajectories within individuals. From a developmental, life-course perspective, withinperson change is ongoing and ever present.

\section{B. Future Research}

A major issue in the study of desistance concerns the availability of data. Much of what we know about desistance-stable noncriminal behavior-is drawn from official data. Are the declines in "official crime" that we see real? Do offenders become more skillful in eluding arrest over time? Do offenders shift to crimes that are less risky with respect to detection and arrest? Do serious offenders drop out because of high mortality or other forms of attrition (see also Gartner and Piliavin 1988)? Much more research is needed on nonofficial sources of data, ranging from self-reports to ethnography to systematic social observation.

From a methodological standpoint, it has been said that one can truly know whether a given offender has truly desisted only in retrospect. Another key issue, then, is, how do we study desistance prospectively? One way would be to study the natural history of crime and provide a better description of the processes of offending over time. Along the same lines, Brownell et al. (1986, p. 778) recommend a research focus on lapses and relapses with respect to problem behavior. Since drinkers, smokers, and binge eaters quit their problem behavior 
more than once, the idea of understanding relapse is compelling. For instance, what is the effect of lapse and relapse on significant others? What are the determinants and predictors of lapse and relapse? What are the consequences of lapse and relapse? Can lapse and relapse be prevented?

Another potentially useful topic would be to study desistance at all phases of life, especially early in the life course as well as later. Conversely, we need to learn more about "off time" onset of criminal activity. Both will provide insights into the desistance process.

Finally, given the role of human agency in the desistance process, we need to find a way to measure individual motivation, free will, and ultimately the decision to initiate and embrace the process of change. From our data, men who desisted were "active participants" in the desistance process, and we need to capture changes in decision making, shifts in the perceptions of the risks and rewards of crime, and fluctuations in the meanings of "doing crime" versus "going straight." A creative integration of quantitative and qualitative research methods in this area could lead to a major contribution to our understanding desistance.

Subgroup Differences and Secular Change. There are several research questions about stability and change in crime over the life course. In our view, the central issue concerns the underlying mechanisms or processes that lead to desistance from crime and other problem behavior, and whether these processes have shifted over time. In our research examining the lives of disadvantaged men who experienced the transition from adolescence to young adulthood in the 1950s and 1960s, we found that desistance from crime was related to job stability, marital attachment, and successful military experiences. However, the extent to which these mechanisms explain desistance from crime today is not known, although the evidence suggests that they do. Linking historical shifts to individual transitions is a central theme of the life course.

Another important question is whether the mechanisms of desistance differ by race, gender, and social class. Although limited, there is some evidence to suggest that there are differential rates of desistance by race (Elliott 1994). More research is needed to determine how the predictors and processes of desistance differ across various subgroups in the population. We expect that variations by race, ethnicity, and structural context in promoting successful transitions to young adulthood will have effects on the desistance process. We know 
that rates of marriage and employment vary by race and social class. We also know neighborhood contexts vary as well, and it is expected that these neighborhood differences will interact with individual differences to increase the probability of crime and violence (Moffitt 1997). But exactly how these interactions between person and context affect the desistance process is the key research question.

Gangs. Thornberry (1998) found that gangs facilitate delinquent behavior, especially violent behavior. Thus, one would expect that gang members would have more difficulty desisting from crime compared with non-gang members. Compared with the literature on joining gangs, the literature on leaving gangs is sparse (see Spergel 1990, pp. 222-26). For those who do leave, the story appears similar to what we learned for non-gang members leaving crime. For example, Curry and Decker (1998, p. 72) reported that in addition to experiencing or witnessing violence, life-course events like employment, marriage, and becoming a parent were the key reasons for leaving a gang. According to Spergel (1990, p. 225), there is growing evidence that gang membership does not end with adolescence. Hagedorn (1988) has also argued that changes in the macrolevel opportunity structure vis-à-vis jobs and marriage have led to continued involvement in gangs among adults and subsequently less desistance from crime. More research is needed on desistance with respect to specific crime types and criminal organizations.

Alcobol. Many studies have established a link between alcohol abuse and serious criminal behavior, including violent crime (see Reiss and Roth 1993). More research is needed to ascertain the role of alcohol abuse in perpetuating crime beyond adolescence. Recently, Nielsen (1999) examined racial/ethnic differences in drunkenness using data from the 1991 National Household Survey on Drug Abuse. She found that whites "aged out" of drunkenness, but African-Americans and Hispanics did not. This is consistent with other literature on the topic (see e.g., Fillmore et al. 1991; but cf. Neff and Dassori 1998). For the overall sample, being employed, going to school, or being married was associated with less frequent drunkenness. This finding is also consistent with other literature indicating that participation in adult social roles is associated with decreased substance abuse (see e.g., MillerTutzauer, Leonard, and Windle 1991; Labouvie 1996). However, perhaps even more important, Nielsen (1999) found differential effects by race/ethnicity. Marriage, for instance, inhibited drunkenness for whites but had no effect for African-Americans. The marriage effect 
for Hispanics was not especially strong. Further study of this issue will provide a better understanding of the linkage between alcohol use, violent behavior, and desistance from crime (see also Fagan 1990, pp. 270-76).

\section{Future Policy}

One of the major policy issues of the day concerns whether criminal justice sanctions foster recidivism or help lead to the termination of offending. This issue has had a long and protracted history in criminology, and we cannot hope to do it justice here. Still, we believe that desistance research has yielded some sturdy findings that offer sobering implications for many taken-for-granted assumptions that pervade the policy arena.

Perhaps the most salient finding concerns the possible counterproductive effects of punitive sanctions when considered in the long run of individual lives. In our research program analyzing the Gluecks' data, for example, we examined the role of criminal behavior and reactions to it by the criminal justice system over the course of adolescence and young and middle adulthood. We found that delinquent behavior has a systematic attenuating effect on the social and institutional bonds that normally link adults to society (e.g., labor force attachment, marital cohesion). More specifically, we found that social bonds to employment were directly influenced by criminal sanctions-incarceration as a juvenile and as a young adult had a negative effect on later job stability, which in turn was negatively related to continued involvement in crime over the life course (see also Fagan and Freeman 1999).

From this finding as well as other suggestive evidence (see Freeman 1991; Nagin and Waldfogel 1995) we have pursued the idea of "cumulative continuity," which posits that delinquency incrementally mortgages the future by generating negative consequences for the life chances of stigmatized and institutionalized youth (see Sampson and Laub 1997). Arrest and especially incarceration may spark failure in school, unemployment, and weak community bonds, which in turn increase adult crime. Serious delinquency in particular leads to the "knifing off" of future opportunities such that participants have fewer options for a conventional life. Our analysis of the Gluecks' data showed that the effects of long periods of incarceration were most severe when manifested in early adolescence-many of the Glueck juveniles were simply cut off from the most promising avenues for later desistance from crime. This finding is consistent with Western and 
Beckett's recent study of a contemporary sample showing that the negative effects of youth incarceration on adult employment time exceeds the large negative effects for dropping out of high school and living in an area with high unemployment (1999, p. 1048).

There is, of course, a long line of criminological research focusing on the potential backfiring of official sanctions and the role of stigma in generating further crime and deviance (for a review, see Paternoster and Iovanni [1989]; Sampson and Laub [1997]). More recently, Sherman (1993) has developed the idea of defiance as a possible response to the formal sanctioning process. In the arena of substance abuse, Biernacki (1986, p. 185) has argued that the acceptance of ex-addicts into normal social worlds is essential for the recovery process. This line of inquiry in criminology is relevant to policies based on deterrence and other forms of punitive intervention; simply put, we need to take into account the potential negative side effects of sanctioning for fostering desistance, along with factors that facilitate offender reintegration.

Perhaps the silver lining can be found in another of the major conclusions from our long-term study of the Glueck delinquents: intraindividual change is widespread even among a large group of individuals labeled as serious, persistent juvenile delinquents and possessing all the risk characteristics that many believe are enduring and stable across the life course. From a policy standpoint, the message is that change is possible, and therefore it is critical that individuals are given the opportunity to reconnect to institutions like family, school, and work after a period of incarceration or any criminal justice contact for that matter (Cook 1975; Braithwaite 1989). This is not to say that rehabilitation efforts or other forms of therapeutic intervention necessarily foster desistance. In many instances, they do not. What we are urging is that policy makers consider the risks and benefits of interventions for other domains of life that in an indirect way affect later outcomes. Much as for criminals who lack self-control, incarceration policies that appear to policy makers to be a wise move in the short run may appear less so over the long haul.

Abbott, Andrew. 1997. "On the Concept of Turning Point." Comparative Social Research 16:85-105. 
Adler, Patricia A. 1992. "The 'Post' Phase of Deviant Careers: Reintegrating Drug Traffickers." Deviant Behavior 13:103-26.

Adler, Patricia A., and Peter Adler. 1983. "Shifts and Oscillations in Deviant Careers: The Case of Upper-Level Drug Dealers and Smugglers." Social Problems 31:195-207.

Agnew, Robert. 1997. "Stability and Change in Crime over the Life Course: A Strain Theory Explanation." In Developmental Theories of Crime and Delinquency, edited by Terence P. Thornberry. New Brunswick, N.J.: Transaction.

Akers, Ronald L. 1990. "Rational Choice, Deterrence, and Social Learning in Criminology: The Path Not Taken." Fournal of Criminal Law and Criminology 81:653-76.

. 1998. Social Learning and Social Structure: A General Theory of Crime and Deviance. Boston: Northeastern University Press.

Andrews, D. A., and James Bonta. 1994. The Psychology of Criminal Conduct. Cincinnati: Anderson.

Andrews, D. A., James Bonta, and Robert D. Hoge. 1990. "Classification for Effective Rehabilitation: Rediscovering Psychology." Criminal Fustice and Behavior 17:19-52.

Barnett, Arnold, Alfred Blumstein, and David P. Farrington. 1989. "A Prospective Test of a Criminal Career Model." Criminology 27:373-85.

Barnett, Arnold, and Anthony J. Lofaso. 1985. "Selective Incapacitation and the Philadelphia Cohort Data." Fournal of Quantitative Criminology 1:3-36.

Barr, Robert, and Ken Pease. 1990. "Crime Placement, Displacement, and Deflection." In Crime and Fustice: A Review of Research, vol. 12, edited by Michael Tonry and Norval Morris. Chicago: University of Chicago Press.

Baskin, Deborah R., and Ira B. Sommers. 1998. Casualties of Community Disorder: Women's Careers in Violent Crime. Boulder, Colo.: Westview Press.

Becker, Howard S. 1960. "Notes on the Concept of Commitment." American Fournal of Sociology 66:32-40.

Biernacki, Patrick. 1986. Patbways from Heroin Addiction Recovery without Treatment. Philadelphia: Temple University Press.

Blumstein, Alfred, and Jacqueline Cohen. 1987. "Characterizing Criminal Careers." Science 237:985-91.

Blumstein, Alfred, Jacqueline Cohen, Jeffrey Roth, and Christy Visher, eds. 1986. Criminal Careers and "Career Criminals." Washington, D.C.: National Academy Press.

Blumstein, Alfred, David P. Farrington, and Soumyo Moitra. 1985. "Delinquency Careers: Innocents, Desisters, and Persisters." In Crime and 7ustice: An Annual Review of Research, vol. 6, edited by Michael Tonry and Norval Morris. Chicago: University of Chicago Press.

Bonta, James. 1996. "Risk-Needs Assessment and Treatment." In Choosing Correctional Options That Work, edited by Alan Harland. Thousand Oaks, Calif.: Sage.

Braithwaite, John. 1989. Crime, Shame, and Reintegration. Cambridge: Cambridge University Press.

Briar, Scott, and Irving Piliavin. 1965. "Delinquency, Situational Inducements, and Commitment to Conformity." Social Problems 13:35-45. 
Brownell, Kelly D., G. Alan Marlatt, Edward Lichtenstein, and G. Terence Wilson. 1986. "Understanding and Preventing Relapse." American Psycbologist 41:765-82.

Bushway, Shawn, Alex Piquero, Lisa Briody, Elizabeth Cauffman, and Paul Mazerolle. 2001. "An Empirical Framework for Studying Desistance as a Process." Criminology (forthcoming).

Capaldi, Deborah M., and Gerald R. Patterson. 1996. "Can Violent Offenders Be Distinguished from Frequent Offenders? Prediction from Childhood to Adolescence." Fournal of Research in Crime and Delinquency 33:206-31.

Caspi, Avshalom, and Terrie E. Moffitt. 1995. "The Continuity of Maladaptive Behavior: From Description to Understanding in the Study of Antisocial Behavior." In Developmental Psychopathology, vol. 2, Risk Disorder, and Adaptation, edited by Dante Cicchetti and Donald J. Cohen. New York: Wiley.

Chen, Kevin, and Denise B. Kandel. 1995. "The Natural History of Drug Use from Adolescence to the Mid-Thirties in a General Population Sample." American Fournal of Public Health 85:41-47.

- 1998. "Predictors of Cessation of Marijuana Use: An Event History Analysis." Drug and Alcobol Dependence 50:109-21.

Clarke, Ronald V., and Derek B. Cornish. 1985. "Modeling Offenders' Decisions: A Framework for Research and Policy." In Crime and fustice: An Annual Review of Research, vol. 6, edited by Michael Tonry and Norval Morris. Chicago: University of Chicago Press.

Cline, Hugh F. 1980. "Criminal Behavior over the Life Span." In Constancy and Change in Human Development, edited by Orville G. Brim, Jr., and Jerome Kagan. Cambridge, Mass.: Harvard University Press.

Cohen, Lawrence E., and Bryan J. Vila. 1996. "Self-Control and Social Control: An Exposition of the Gottfredson-Hirschi/Sampson-Laub Debate." Studies on Crime and Crime Prevention 5:125-50.

Cohler, Bertram. 1982. "Personal Narrative and Life Course." In Life Span Development and Bebavior, vol. 4, edited by Paul B. Baltes and Orville G. Brim, Jr. New York: Academic Press.

Cook, Philip. 1975. "The Correctional Carrot: Better Jobs for Parolees." Policy Analysis 1:11-54.

Cornish, Derek B., and Ronald V. Clarke. 1986. The Reasoning Criminal: Rational Choice Perspectives on Offending. New York: Springer.

Cromwell, Paul F., James N. Olson, and D'Aunn Wester Avary. 1991. Breaking and Entering: An Ethnographic Analysis of Burglary. Newbury Park, Calif.: Sage.

Cullen, Francis. 1994. "Social Support as an Organizing Concept for Criminology: Presidential Address to the Academy of Criminal Justice Sciences." Fustice Quarterly 11:527-59.

Curry, G. David, and Scott H. Decker. 1998. Confronting Gangs: Crime and Community. Los Angeles: Roxbury.

Cusson, Maurice, and Pierre Pinsonneault. 1986. "The Decision to Give Up Crime." In The Reasoning Criminal: Rational Choice Perspectives on Offending, edited by Derek B. Cornish and Ronald V. Clarke. New York: Springer. 
Denzin, Norman K. 1989. Interpretive Interactionism. Newbury Park, Calif.: Sage.

D’Unger, Amy, Kenneth C. Land, Patricia McCall, and Daniel S. Nagin. 1998. "How Many Latent Classes of Delinquent/Criminal Careers? Results from Mixed Poisson Regression Analyses." American fournal of Sociology 103:1593-1630.

Elder, Glen H., Jr. 1998. "The Life Course as Developmental Theory." Child Development 69:1-12.

Elliott, Delbert S. 1994. "Serious Violent Offenders: Onset, Developmental Course, and Termination." Criminology 32:1-22.

Elliott, Delbert S., David Huizinga, and Scott Menard. 1989. Multiple Problem Youth: Delinquency, Substance Use, and Mental Health Problems. New York: Springer.

Emirbayer, Mustafa, and Ann Mische. 1998. "What Is Agency?" American fournal of Sociology 103:962-1023.

Esbensen, Finn-Age, and Delbert S. Elliott. 1994. "Continuity and Discontinuity in Illicit Drug Use: Patterns and Antecedents." Fournal of Drug Issues 24:75-97.

Fagan, Jeffrey. 1989. "Cessation of Family Violence: Deterrence and Dissuasion. In Family Violence, edited by Lloyd Ohlin and Michael Tonry. Vol. 11 of Crime and 7ustice: A Review of Research, edited by Michael Tonry and Norval Morris. Chicago: University of Chicago Press.

- 1990. "Intoxication and Aggression." In Drugs and Crime, edited by Michael Tonry and James Q. Wilson. Vol. 13 of Crime and Justice: A Review of Research, edited by Michael Tonry. Chicago: University of Chicago Press.

Fagan, Jeffrey, and Richard B. Freeman. 1999. "Crime and Work." In Crime and 7ustice: A Review of Research, vol. 25, edited by Michael Tonry. Chicago: University of Chicago Press.

Farrall, Stephen, and Benjamin Bowling. 1999. "Structuration, Human Development, and Desistance from Crime." British fournal of Criminology 39:25368.

Farrington, David P. 1986. "Age and Crime." In Crime and fustice: An Annual Review of Research, vol. 7, edited by Michael Tonry and Norval Morris. Chicago: University of Chicago Press.

. 1991. "Childhood Aggression and Adult Violence: Early Precursors and Later Life Outcomes." In The Development and Treatment of Childbood Aggression, edited by Daniel J. Pepler and Kenneth H. Rubin. Hillsdale, N.J.: Erlbaum.

. 1992. "Explaining the Beginning, Progress, and Ending of Antisocial Behavior from Birth to Adulthood." In Facts, Frameworks, and Forecasts, edited by Joan McCord. New Brunswick, N.J.: Transaction.

Farrington, David P., Bernard Gallagher, Lynda Morley, Raymond J. St. Ledger, and Donald J. West. 1986. "Unemployment, School Leaving, and Crime." British fournal of Criminology 26:335-56.

-. 1988. "Cambridge Study in Delinquent Development: Long-Term Follow-Up." Unpublished manuscript. Institute of Criminology, Cambridge University. 
Farrington, David P., and J. David Hawkins. 1991. "Predicting Participation, Early Onset, and Later Persistence in Officially Recorded Offending." Criminal Behaviour and Mental Health 1:1-33.

Farrington, David P., Sandra Lambert, and Donald J. West. 1998. "Criminal Careers of Two Generations of Family Members in the Cambridge Study in Delinquent Development." Studies on Crime and Crime Prevention 7:85106.

Farrington, David P., and Donald J. West. 1995. "Effects of Marriage, Separation, and Children on Offending by Adult Males." In Current Perspectives on Aging and the Life Cycle, vol. 4, edited by Zena Blau and John Hagan. Greenwich, Conn.: JAI Press.

Feld, Scott L., and Murray A. Straus. 1989. "Escalation and Desistance of Wife Assault in Marriage." Criminology 27:141-61.

Fillmore, Kaye Middleton, Elizabeth Hartka, Bryan M. Johnstone, E. Victor Leino, Michelle Motoyoshi, and Mark T. Temple. 1991. "A Meta-analysis of Life Course Variation in Drinking." British fournal of Addiction 86:122168.

Fisher, Edwin B., Jr., Edward Lichenstein, Debra Haire-Joshu, Glen D. Morgan, and Heather R. Rehberg. 1993. "Methods, Successes, and Failures of Smoking Cessation Programs." Annual Review of Medicine 44:481-513.

Freeman, Richard. 1991. "Crime and the Employment of Disadvantaged Youth." Working Paper. Cambridge, Mass.: Harvard University, National Bureau of Economic Research.

Gartner, Rosemary, and Irving Piliavin. 1988. "The Aging Offender and the Aged Offender." In Life-Span Development and Behavior, vol. 9, edited by Paul B. Baltes, David L. Featherman, and Richard M. Lerner. Hillside, N.J.: Erlbaum.

Gendreau, Paul. 1996. "The Principles of Effective Intervention with Offenders." In Choosing Correctional Options That Work, edited by Alan Harland. Thousand Oaks, Calif.: Sage.

Gendreau, Paul, Francis T. Cullen, and James Bonta. 1994. "Intensive Rehabilitation Supervision: The Next Generation in Community Corrections?" Federal Probation 58:72-78.

Gibbens, T. C. N. 1984. "Borstal Boys after 25 Years." British Fournal of Criminology 24:49-62.

Giordano, Peggy C., Stephen A. Cernkovich, and Jennifer L. Rudolph. 2000. "Gender, Crime, and Desistance: Toward a Theory of Cognitive Transformation." Unpublished manuscript. Bowling Green, Ohio: Bowling Green State University.

Glaser, Daniel. 1969. The Effectiveness of a Prison and Parole System. Abridged ed. Indianapolis: Bobbs-Merrill.

Glassner, Barry, Margaret Ksander, Bruce Berg, and Bruce D. Johnson. 1983. "A Note on the Deterrent Effect of Juvenile vs. Adult Jurisdiction." Social Problems 31:219-21.

Glueck, Sheldon, and Eleanor Glueck. 1940. Fuvenile Delinquents Grown Up. New York: Commonwealth Fund. 1943. Criminal Careers in Retrospect. New York: Commonwealth Fund. 
1945. After-Conduct of Discharged Offenders. London: Macmillan. Fund. 1950. Unraveling Fuvenile Delinquency. New York: Commonwealth

Harvard University Press.

-1974. Of Delinquency and Crime. Springfield, Ill.: Charles C. Thomas.

Gottfredson, Michael R., and Travis Hirschi. 1990. A General Theory of Crime. Stanford, Calif.: Stanford University Press.

Gove, Walter R. 1985. "The Effect of Age and Gender on Deviant Behavior: A Biopsychosocial Perspective." In Gender and the Life Course, edited by Alice S. Rossi. New York: Aldine.

Graham, John, and Benjamin Bowling. 1995. Young People and Crime. Research Study 145. London: Home Office.

Hagedorn, John M. 1988. People and Folks: Gangs, Crime, and the Underclass in a Rustbelt City. Chicago: Lake View Press.

Hill, Thomas W. 1971. "From Hell-Raiser to Family Man." In Conformity and Conflict: Readings in Cultural Anthropology, edited by James P. Spradley and David W. McCurdy. Boston: Little, Brown.

Hirschi, Travis. 1969. Causes of Delinquency. Berkeley: University of California Press.

Hirschi, Travis, and Michael R. Gottfredson. 1983. "Age and the Explanation of Crime." American Fournal of Sociology 89:552-84.

- 1986. "The Distinction between Crime and Criminality." In Critique and Explanation: Essays in Honor of Gwynne Nettler, edited by Timothy F. Hartnagel and Robert A. Silverman. New Brunswick, N.J.: Transaction.

Hoffman, Peter B., and James L. Beck. 1984. "Burnout-Age at Release from Prison and Recidivism." Fournal of Criminal fustice 12:617-23.

Horney, Julie D. Wayne Osgood, and Ineke Haen Marshall. 1995. "Criminal Careers in the Short-Term: Intra-individual Variability in Crime and Its Relation to Local Life Circumstances." American Sociological Review 60:65573.

Hughes, Margaret. 1998. "Turning Points in the Lives of Young Inner-City Men Forgoing Destructive Criminal Behaviors: A Qualitative Study." Social Work Research 22:143-51.

Irwin, John. 1970. The Felon. Englewood Cliffs, N.J.: Prentice Hall.

Kandel, Denise B., and Kazuo Yamaguchi. 1987. "Job Mobility and Drug Use: An Event History Analysis." American Fournal of Sociology 92:836-78.

Knight, B. J., S. G. Osborn, and Donald J. West. 1977. "Early Marriage and Criminal Tendency in Males." British Fournal of Criminology 17:348-60.

Labouvie, Erich. 1996. "Maturing Out of Substance Use: Selection and SelfCorrection." Fournal of Drug Issues 26:457-76.

Lattimore, Pamela K., Richard L. Linster, and John M. MacDonald. 1997. "Risk of Death among Serious Young Offenders." Fournal of Research in Crime and Delinquency 34:187-209.

Laub, John H., Daniel S. Nagin, and Robert J. Sampson. 1998. "Trajectories of Change in Criminal Offending: Good Marriages and the Desistance Process." American Sociological Review 63:225-38. 
Laub, John H., and Robert J. Sampson. 1993. "Turning Points in the Life Course: Why Change Matters to the Study of Crime." Criminology 31:301-25.

- 2001. Boys in Trouble and How They Age. Cambridge, Mass.: Harvard University Press.

LeBlanc, Marc, and Marcel Frechette. 1989. Male Criminal Activity from Childbood through Youth: Multilevel and Developmental Perspectives. New York: Springer.

LeBlanc, Marc, and Rolf Loeber. 1993. "Precursors, Causes, and the Development of Criminal Offending." In Precursors and Causes in Development and Psychopathology, edited by Dale F. Hay and Adrian Angold. New York: Wiley.

. 1998. "Developmental Criminology Updated." In Crime and Fustice: A Review of Research, vol. 23, edited by Michael Tonry. Chicago: University of Chicago Press.

Leibrich, Julie. 1996. "The Role of Shame in Going Straight: A Study of Former Offenders." In Restorative Fustice: International Perspectives, edited by Burt Galaway and Joe Hudson. Monsey, N.Y.: Criminal Justice Press.

Lewontin, Richard. 2000. The Triple Helix: Gene, Organism, and Environment. Cambridge, Mass.: Harvard University Press.

Loeber, Rolf, and Marc LeBlanc. 1990. "Toward a Developmental Criminology." In Crime and 7ustice: A Review of Research, vol. 12, edited by Michael Tonry and Norval Morris. Chicago: University of Chicago Press.

Loeber, Rolf, Magda Stouthamer-Loeber, Welmoet Van Kammen, and David P. Farrington. 1991. "Initiation, Escalation, and Desistance in Juvenile Offending and Their Correlates." Fournal of Criminal Law and Criminology 82: 36-82.

Lofland, John. 1969. Deviance and Identity. Englewood Cliffs, N.J.: PrenticeHall.

Maruna, Shadd. 1997. "Going Straight: Desistance from Crime and Life Narratives of Reform." In The Narrative Study of Lives, vol. 5, edited by Amia Lieblich and Ruthellen Josselson. Thousand Oaks, Calif.: Sage.

- 2001. Making Good: How Ex-offenders Reform and Reclaim Their Lives. Washington, D.C.: American Psychological Association Books.

Matsueda, Ross L., and Karen Heimer. 1997. "A Symbolic Interactionist Theory of Role-Transitions, Role Commitments, and Delinquency." In Developmental Theories of Crime and Delinquency, edited by Terence Thornberry. New Brunswick, N.J.: Transaction.

Matza, David. 1964. Delinquency and Drift. New York: Wiley.

McCord, Joan. 1980. "Patterns of Deviance." In Human Functioning in Longitudinal Perspective, edited by Saul B. Sells, Rick Crandall, Merrill Roff, John S. Strauss, and William Pollin. Baltimore: Williams \& Wilkins.

Meisenhelder, Thomas. 1977. "An Exploratory Study of Exiting from Criminal Careers." Criminology 15:319-34.

Miller-Tutzauer, Carol, Kenneth E. Leonard, and Michael Windle. 1991. "Marriage and Alcohol Use: A Longitudinal Study of "Maturing Out.", Fournal of Studies on Alcobol 52:434-40.

Mischkowitz, Robert. 1994. "Desistance from a Delinquent Way of Life?" In Cross-National Longitudinal Research on Human Development and Criminal Be- 
bavior, edited by Elmar G. M. Weitekamp and Hans-Jurgen Kerner. Dordrecht: Kluwer Academic.

Moffitt, Terrie E. 1994. "Natural Histories of Delinquency." In Cross-National Longitudinal Research on Human Development and Criminal Behavior, edited by Elmar G. M. Weitekamp and Hans-Jurgen Kerner. Dordrecht: Kluwer Academic.

-1 1997. "Neuropsychology, Antisocial Behavior, and Neighborhood Context." In Violence and Childhood in the Inner City, edited by Joan McCord. Cambridge: Cambridge University Press.

Mulvey, Edward P., and Mark Aber. 1988. "Growing Out of Delinquency: Development and Desistance." In The Abandonment of Delinquent Bebavior, edited by Richard L. Jenkins and Waln K. Brown. New York: Praeger Publishers.

Mulvey, Edward P., and John F. LaRosa. 1986. "Delinquency Cessation and Adolescent Development: Preliminary Data." American fournal of Orthopsychiatry 56:212-24.

Nagin, Daniel, David P. Farrington, and Terrie E. Moffitt. 1995. "LifeCourse Trajectories of Different Types of Offenders." Criminology 33:11139.

Nagin, Daniel S., and Kenneth C. Land. 1993. "Age, Criminal Careers, and Population Heterogeneity: Specification and Estimation of a Nonparametric, Mixed Poisson Model." Criminology 31:327-59.

Nagin, Daniel S., and Raymond Paternoster. 1991. "On the Relationship of Past and Future Participation in Delinquency." Criminology 29:163-90.

- 1994. "Personal Capital and Social Control: The Deterrence Implications of Individual Differences in Criminal Offending." Criminology 32:581-606.

Nagin, Daniel S., and Joel Waldfogel. 1995. "The Effects of Criminality and Conviction on the Labor Market Status of Young British Offenders." International Review of Law and Economics 15:107-26.

Neff, James Alan, and Albana M. Dassori. 1998. "Age and Maturing Out of Heavy Drinking among Anglo and Minority Male Drinkers: A Comparison of Cross-Sectional Data and Retrospective Drinking History Techniques." Hispanic Fournal of Behavioral Sciences 20:225-40.

Neugarten, Bernice L. 1996. The Meanings of Age: Selected Papers of Bernice L. Neugarten. Chicago: University of Chicago Press.

Nielsen, Amie L. 1999. "Testing Sampson and Laub's Life Course Theory: Age, Race/Ethnicity, and Drunkenness." Deviant Behavior 20:129-51.

Osborn, S. G. 1980. "Moving Home, Leaving London, and Delinquent Trends." British fournal of Criminology 20:54-61.

Osborn, S. G., and Donald J. West. 1979. "Marriage and Delinquency: A Postscript." British Fournal of Criminology 19:254-56.

Osgood, D. Wayne, and Hyunkee Lee. 1993. "Leisure Activities, Age, and Adult Roles across the Lifespan." Society and Leisure 16:181-208.

Osgood, D. Wayne, Janet K. Wilson, Patrick M. O'Malley, Jerald G. Bachman, and Lloyd D. Johnston. 1996. "Routine Activities and Individual Deviant Behavior." American Sociological Review 61:635-55. 
Paternoster, Raymond. 1989. "Decisions to Participate in and Desist from Four Types of Common Delinquency: Deterrence and the Rational Choice Perspective." Law and Society Review 23:7-40.

Paternoster, Raymond, and Leeann Iovanni. 1989. "The Labeling Perspective and Delinquency: An Elaboration of the Theory and an Assessment of the Evidence." Fustice Quarterly 6:359-94.

Pezzin, Liliana E. 1995. "Earning Prospects, Matching Effects, and the Decision to Terminate a Criminal Career." Fournal of Quantitative Criminology $11: 29-50$.

Piquero, Alex R. 2000. "Frequency, Specialization, and Violence in Offending Careers." Fournal of Research in Crime and Delinquency 37:392-418.

Piquero, Alex R., Alfred Blumstein, Robert Brame, Rudy Haapanen, Edward P. Mulvey, and Daniel S. Nagin. 2001. "Assessing the Impact of Exposure Time and Incapacitation on Longitudinal Trajectories of Criminal Offending." Fournal of Adolescent Research 16:54-74.

Prochaska, James, Carlo DiClemente, and John Norcross. 1992. "In Search of How People Change: Applications to Addictive Behaviors." American Psychologist 47:1102-14.

Prochaska, James O., and Wayne F. Velicer. 1997. "The Transtheoretical Model of Health Behavior Change." American Fournal of Health Promotion 12:38-48.

Quigley, Brian M., and Kenneth E. Leonard. 1996. "Desistance of Husband Aggression in the Early Years of Marriage." Violence and Victims 11:355-70.

Rand, Alicia. 1987. "Transitional Life Events and Desistance from Delinquency and Crime." In From Boy to Man, from Delinquency to Crime, edited by Marvin E. Wolfgang, Terence P. Thornberry, and Robert M. Figlio. Chicago: University of Chicago Press.

Reiss, Albert J., Jr. 1989. "Ending Criminal Careers.” Final Report prepared for the Desistance/Persistence Working Group of the Program on Human Development and Criminal Behavior. MacArthur Foundation and National Institute of Justice.

Reiss, Albert J., Jr., and Jeffrey A. Roth. 1993. Understanding and Preventing Violence. Washington, D.C.: National Academy Press.

Ricks, Thomas E. 1997. "U.S. Infantry Surprise: It's Now Mostly White; Blacks Hold Office Jobs." Wall Street Fournal (January 6), pp. A1, A6.

Robins, Lee. 1966. Deviant Children Grown Up. Baltimore: Williams \& Wilkins.

Rutter, Michael. 1988. "Longitudinal Data in the Study of Causal Processes: Some Uses and Some Pitfalls." In Studies of Psychosocial Risk: The Power of Longitudinal Data, edited by Michael Rutter. Cambridge: Cambridge University Press.

Rutter, Michael, David Quinton, and Jonathan Hill. 1990. "Adult Outcomes of Institution-Reared Children: Males and Females Compared." In Straight and Devious Patbways from Childbood to Adulthood, edited by Lee Robins and Michael Rutter. Cambridge: Cambridge University Press.

Sampson, Robert, J. 2000. "On the Social Development of Antisocial Behavior: A Review Essay." Social Development 9:565-68. 
Sampson, Robert J., and John H. Laub. 1993. Crime in the Making: Patbways and Turning Points through Life. Cambridge, Mass.: Harvard University Press.

1995. "Understanding Variability in Lives through Time: Contributions of Life-Course Criminology." Studies on Crime and Crime Prevention 4:143-58.

1996. "Socioeconomic Achievement in the Life Course of Disadvantaged Men: Military Service as a Turning Point, Circa 1940-1965." American Sociological Review 61:347-67.

- 1997. "A Life-Course Theory of Cumulative Disadvantage and the Stability of Delinquency." In Developmental Theories of Crime and Delinquency, edited by Terence P. Thornberry. New Brunswick, N.J.: Transaction.

Sarnecki, Jerzy. 1985. Predicting Social Maladjustment. Stockbolm Boys Grown Up, 1. Research Report 17. Stockholm: National Council for Crime Prevention. Sherman, Lawrence W. 1993. "Defiance, Deterrence, and Irrelevance: A Theory of the Criminal Sanction." Fournal of Research in Crime and Delinquency $30: 445-73$.

Shover, Neal. 1985. Aging Criminals. Beverly Hills, Calif.: Sage.

- 1996. Great Pretenders: Pursuits and Careers of Persistent Thieves. Boulder, Colo.: Westview Press.

Shover, Neal, and Carol Y. Thompson. 1992. "Age, Differential Expectations, and Crime Desistance." Criminology 30: 89-104.

Smelser, Neil J. 1998. "The Rational and the Ambivalent in the Social Sciences." American Sociological Review 63:1-15.

Sobell, Linda C., Mark B. Sobell, Tony Toneatto, and Gloria I. Leo. 1993. "What Triggers the Resolution of Alcohol Problems without Treatment?" Alcobolism: Clinical and Experimental Researcb 17:217-24.

Sommers, Ira, Deborah R. Baskin, and Jeffrey Fagan. 1994. "Getting Out of the Life: Crime Desistance by Female Street Offenders." Deviant Behavior 15:125-49.

Spergel, Irving A. 1990. "Youth Gangs: Continuity and Change." In Crime and fustice: A Review of Research, vol. 12, edited by Michael Tonry and Norval Morris. Chicago: University of Chicago Press.

Stall, Robb, and Patrick Biernacki. 1986. "Spontaneous Remission from the Problematic Use of Substances: An Inductive Model Derived from a Comparative Analysis of the Alcohol, Opiate, Tobacco, and Food/Obesity Literatures." International Fournal of the Addictions 21:1-23.

Stattin, Hakan, and David Magnusson. 1991. "Stability and Change in Criminal Behavior Up to Age 30." British Fournal of Criminology 31:327-46.

Stattin, Hakan, David Magnusson, and Howard Reichel. 1989. "Criminal Activity at Different Ages." British fournal of Criminology 29:368-85.

Steffensmeier, Darrell J., Emile Andersen Allan, Miles D. Harer, and Cathy Streifel. 1989. "Age and the Distribution of Crime." American fournal of Sociology 94:803-31.

Suitor, J. Jill, Karl Pillemer, and Murray A. Straus. 1990. "Marital Violence in a Life Course Perspective." In Physical Violence in American Families, edited 
by Murray A. Straus and Richard J. Gelles. New Brunswick, N.J.: Transaction.

Sullivan, Mercer. 1989. Getting Paid. Ithaca, N.Y.: Cornell University Press. Temple, Mark T., Kaye Middleton Fillmore, Elizabeth Hartka, Bryan M. Johnstone, E. Victor Leino, and Michelle Motoyoshi. 1991. "A Meta-analysis of Change in Marital and Employment Status as Predictors of Alcohol Consumption on a Typical Occasion." British fournal of Addiction 86:126981.

Thornberry, Terence P. 1987. "Toward an Interactional Theory of Delinquency." Criminology 25:863-91.

1. 1998. "Membership in Youth Gangs and Involvement in Serious and Violent Offending." In Serious and Violent fuvenile Offenders: Risk Factors and Successful Interventions, edited by Rolf Loeber and David P. Farrington. Thousand Oaks, Calif.: Sage.

Tracy, Paul E., and Kimberly Kempf-Leonard. 1996. Continuity and Discontinuity in Criminal Careers. New York: Plenum.

Tracy, Paul E., Marvin E. Wolfgang, and Robert M. Figlio. 1985. Delinquency in Two Birth Cohorts: Executive Summary. Washington, D.C.: Government Printing Office.

Trasler, Gordon. 1979. "Delinquency, Recidivism, and Desistance." British fournal of Criminology 19:314-22.

Tremblay, Richard E. 1994. "Desistance from Crime: Towards a Life-Course Perspective." Discussant Paper presented at the International Society for the Study of Behavioral Development, Amsterdam, June 28-July 2.

Uggen, Christopher. 1999. "Ex-offenders and the Conformist Alternative: A Job Quality Model of Work and Crime." Social Problems 46:127-51.

- 2000. "Work as a Turning Point in the Life Course of Criminals: A Duration Model of Age, Employment, and Recidivism." American Sociological Review 65:529-46.

Uggen, Christopher, and Candace Kruttschnitt. 1998. "Crime in the Breaking: Gender Differences in Desistance." Law and Society Review 32:339-66.

Uggen, Christopher, and Irving Piliavin. 1998. "Asymmetrical Causation and Criminal Desistance." Fournal of Criminal Law and Criminology 88:1399_ 1422.

Vaillant, George E. 1973. "A 20-Year Follow-up of New York Narcotic Addicts." Archives of General Psychiatry 29:237-41.

1988. "What Can Long-Term Follow-up Teach Us about Relapse and Prevention of Relapse in Addiction?" British Fournal of Addiction $83: 1147-57$.

- 1995. The Natural History of Alcobolism Revisited. Cambridge, Mass.: Harvard University Press.

- 1996. "A Long-Term Follow-up of Male Alcohol Abuse." Arcbives of General Psychiatry 53:243-49.

Vaillant, George E., and Eva S. Milofsky. 1982. "Natural History of Male Alcoholism. IV. Paths to Recovery." Archives of General Psychiatry 39:127-33.

Vaughan, Diane. 1986. Uncoupling: Turning Points in Intimate Relationships. New York: Vintage. 
Waldorf, Dan, Craig Reinarman, and Sheigla Murphy. 1991. Cocaine Changes: The Experience of Using and Quitting. Philadelphia: Temple University Press. Warr, Mark. 1993. "Age, Peers, and Delinquency." Criminology 31:17-40. 1998. "Life-Course Transitions and Desistance from Crime." Criminology 36:183-216.

Weitekamp, Elmar G. M., and Hans-Jurgen Kerner. 1994. "Epilogue: Workshop and Plenary Discussions, and Future Directions." In Cross-National Longitudinal Research on Human Development and Criminal Behavior, edited by Elmar G. M. Weitekamp and Hans-Jurgen Kerner. Dordrecht: Kluwer Academic.

West, Donald J. 1982. Delinquency: Its Roots, Careers, and Prospects. London: Heinemann.

Western, Bruce, and Katherine Beckett. 1999. "How Unregulated Is the U.S. Labor Market? The Penal System as a Labor Market Institution." American Fournal of Sociology 104:1030-60.

White, Helene Raskin, and Marsha E. Bates. 1995. "Cessation from Cocaine Use." Addiction 90:947-57.

Wilson, James Q., and Richard J. Herrnstein. 1985. Crime and Human Nature. New York: Simon \& Schuster.

Wilson, William Julius. 1996. When Work Disappears: The World of the New Urban Poor. New York: Knopf.

Woffordt, Sharon, Delbert Elliott, and Scott Menard. 1994. "Continuities in Marital Violence" Fournal of Family Violence 9:195-225.

Wolfgang, Marvin E. 1995. "Transitions of Crime in the Aging Process." In Delinquency and Disrepute in the Life Course: Contextual and Dynamic Analyses, edited by Zena Smith Blau and John Hagan. Greenwich, Conn.: JAI.

Wolfgang, Marvin, Robert Figlio, and Thorsten Sellin. 1972. Delinquency in a Birth Cobort. Chicago: University of Chicago Press.

Wolfgang, Marvin, Terence Thornberry, and Robert Figlio. 1987. From Boy to Man: From Delinquency to Crime. Chicago: University of Chicago Press.

Wright, Kevin N., and Karen E. Wright. 1992. "Does Getting Married Reduce the Likelihood of Criminality? A Review of the Literature." Federal Probation 56:50-56.

Yamaguchi, Kazuo, and Denise B. Kandel. 1985. "On the Resolution of Role Incompatibility: A Life Event History Analysis of Family Roles and Marijuana Use." American fournal of Sociology 90:1284-1325. 